Andrews University

Digital Commons @ Andrews University

\title{
A Study Regarding Organizational Health, Leadership Styles and Practices and Job Satisfaction in the Associacao Central Amazonas of the Seventh-day Adventist Church According to the Perception of the Pastoral Ministry
}

Sergio Alan Alves Caxeta

Andrews University

Follow this and additional works at: https://digitalcommons.andrews.edu/theses

Part of the Leadership Studies Commons, and the Practical Theology Commons

\section{Recommended Citation}

Caxeta, Sergio Alan Alves, "A Study Regarding Organizational Health, Leadership Styles and Practices and Job Satisfaction in the Associacao Central Amazonas of the Seventh-day Adventist Church According to the Perception of the Pastoral Ministry" (2016). Master's Theses. 127.

https://dx.doi.org/10.32597/theses/127

https://digitalcommons.andrews.edu/theses/127

This Thesis is brought to you for free and open access by the Graduate Research at Digital Commons @ Andrews University. It has been accepted for inclusion in Master's Theses by an authorized administrator of Digital Commons@ Andrews University. For more information, please contact repository@andrews.edu. 



\section{ABSTRACT}

A STUDY REGARDING ORGANIZATIONAL HEALTH, LEADERSHIP STYLES AND PRACTICES AND JOB SATISFACTION IN THE ASSOCIAÇÃO CENTRAL AMAZONAS OF THE SEVENTH-DAY ADVENTIST CHURCH ACCORDING TO THE PERCEPTION OF THE PASTORAL MINISTRY

Sérgio Alan Alves Caxeta

Chair: Eliseu Nevil Menegusso 


\section{ABSTRACT OF GRADUATE STUDENT RESEARCH}

Thesis

Andrews University

School of Education

Title: A STUDY REGARDING ORGANIZATIONAL HEALTH, LEADERSHIP STYLES AND PRACTICES AND JOB SATISFACTION IN THE ASSOCIAÇÃO CENTRAL AMAZONAS OF THE SEVENTH-DAY ADVENTIST CHURCH ACCORDING TO THE PERCEPTION OF THE PASTORAL MINISTRY

Name of researcher: Sérgio Alan Alves Caxeta

Name and degree of faculty chair: Eliseu Nevil Menegusso, EdD

Date Completed: July 2016

Problem

Due to the perceived partial insatisfaction on the part of the district pastors and local church leaders in the Associação Central Amazonas (ACeAm) based on the amount of work added to the annual planning and the Organization activities calendar, it was decided to investigate the health organization, the leadership practices and styles, as well as the job satisfaction accrding to the perception of the ACeAm pastoral ministry which may be at the basis of the problem

\section{Method}

The study was conducted among AceAm 59 pastors divided in three leadership categories described as Top Leadership, Management and Work Force 
according to the criteria of OLA the research instrument which analyses the perception of the researched population according to six key areas of leadership, six levels of organizational health, leadership styles and practices and job satisfaction.

\section{Results}

The study showed that the participants perceived the ACeAm organizational health as Moderate, the leadership style as paternal positive, and the Work Force considered the job satisfaction as goob.

\section{Conclusion}

The study lead us to conclude that AceAm has two principal goals to reach: develop servant leadership practices according to the OLA six key areas in order to attain the excellent and optimal level of organizational health and develop the leadership style from paternalist positive towards servant leadership. Regarding job satisfaction, though considered as good, there is room for growth towards very good 


\section{RESUMO DE PESQUISA DE ESTUDANTE DE MESTRADO}

Tese

Andrews University

School of Education

Título: ESTUDO SOBRE A SAÚDE ORGANIZACIONAL, ESTILO E PRÁTICAS DE LIDERANÇA E A SATISFAÇÃO NO TRABALHO DA ASSOCIAÇÃO CENTRAL AMAZONAS DA IGREJA ADVENTISTA DO SÉTIMO DIA SEGUNDO A PERCEPÇÃO DO MINISTÉRIO PASTORAL

Nome do pesquisador: Sérgio Alan Alves Caxeta

Nome e titulação do orientador: Eliseu Nevil Menegusso, EdD.

Data de Conclusão: July 2016

Problema

Devido à percebida parcial insatisfação por parte dos pastores distritais e líderes da igreja local da Associação Central Amazonas (ACeAm) em função do excesso de atividades acrescentadas ao planejamento anual e ao calendário de atividades da Organização, decidiu-se investigar a saúde organizacional, as práticas, os estilos de liderança, e também a satisfação no trabalho segundo a percepção do ministério pastoral da AceAm que podem estar na origem do problema.

Método

O estudo foi realizado entre os 59 pastores da ACeAm divididos em três categorias de liderança descritos como Alta Liderança, Gerência e Força de Trabalho de acordo com os critérios do instrumento de pesquisa OLA que analisa a percepção 
da população pesquisada em seis áreas-chave de liderança, seis níveis de saúde organizacional, estilos e práticas de liderança e a satisfação no trabalho.

\section{Resultados}

O estudo demonstrou que os participantes perceberam a saúde organizacional da ACeAm como Moderada, o estilo de liderança como paternalista positivo, e a categoria Força de Trabalho considerou o nível de satisfação no trabalho como bom.

\section{Conclusão}

A pesquisa possibilitou concluir que a ACeAm tem dois alvos prioritários: desenvolver práticas de liderança servidora de acordo com as seis áreas-chave do OLA para alcançar o nível ótimo e excelente de saúde organizacional e desenvolver o estilo de liderança paternalista positivo crescente em direção à liderança servidora. Sobre a satisfação no trabalho, apesar de ser considerada como boa, há possibilidades de crescimento em direção a satisfação muito bom. 
Andrews University

School of Education

A STUDY REGARDING ORGANIZATIONAL HEALTH, LEADERSHIP STYLES AND PRACTICES AND JOB SATISFACTION IN THE ASSOCIAÇÃO

CENTRAL AMAZONAS OF THE SEVENTH-DAY ADVENTIST

CHURCH ACCORDING TO THE PERCEPTION OF THE

PASTORAL MINISTRY

\author{
A Thesis \\ Presented in Partial Fulfillment \\ of the Requirements for the Degree \\ Master of Arts
}

by

Sérgio Alan Alves Caxeta

2016 
CCopyright by Sérgio Alan Alves Caxeta 2016 All Rights Reserved 
A STUDY REGARDING ORGANIZATIONAL HEALTH, LEADERSHIP STYLES AND PRACTICES AND JOB SATISFACTION IN THE ASSOCIAÇÃO CENTRAL AMAZONAS OF THE SEVENTH-DAY ADVENTIST CHURCH ACCORDING TO THE PERCEPTION OF THE PASTORAL MINISTRY

\author{
A thesis \\ presented in partial fulfillment \\ of the requirements for the degree \\ Master of Arts
}

by

Sérgio Alan Alves Caxeta

APPROVAL BY THE COMMITTEE:

Eliseu Nevil Menegusso, Ed. D.

Josmar S. Arrais de Matos, Ph.D.

Gustavo Gregorutti, Ph. D.

Date approved 
LISTA DE FIGURAS .............................................................................. vi

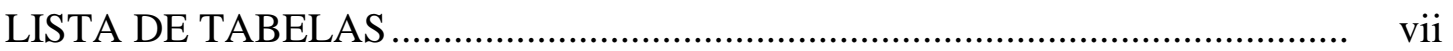

LISTA DE ABREVIAÇÕES ................................................................... viii

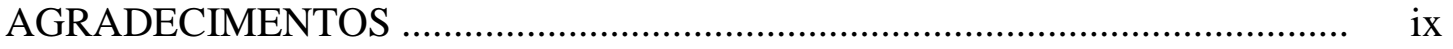

Capítulo

1. INTRODUÇÃO …………………………………………………...

Contexto do Estudo ..........................................................................

Definição do Problema ...................................................................... 6

Propósito do Estudo ........................................................................... 6

Importância do Estudo ............................................................... 7

Preguntas da Pesquisa ..................................................................... 7

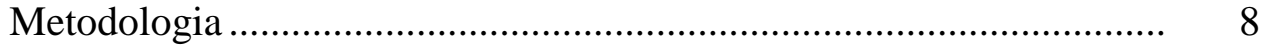

Definição de Termos ...................................................................... 8

Delimitações do Estudo ........................................................................... 11

Organização do Estudo ...................................................................... 11

2. REVISÃO DE LITERATURA …......................................................... 12

Introdução .................................................................................. 12

Conceitos de Liderança .................................................................... 12

Estilos de Liderança .................................................................... 16

Liderança Autoritária ............................................................ 17

Liderança Liberal ................................................................... 18

Liderança Democrática ........................................................... 18

Liderança Visionária .................................................................. 19

Liderança Conselheira ............................................................. 19

Liderança Agregadora..................................................................... 19

Liderança Modelar ................................................................. 20

Teorias de Liderança..................................................................... 20

Teoria dos Traços de Personalidade ............................................ 20

Teoria dos Estilos de Liderança .................................................. 21

Teoria da Liderança Contingencial ou Situacional ......................... 22

Teoria Transformacional.......................................................... 23

Liderança Paternalista .................................................................. 24

Liderança Servidora ......................................................................... 24

As Seis Áreas-Chave da Saúde Organizacional................................... 28 
Valorização de Pessoas .................................................................. 29

Desenvolvimento de Pessoas ......................................................... 31

Construção de Comunidade ........................................................... 33

Demonstração de Autenticidade .................................................. 35

Provisão de Liderança ................................................................ 36

Liderança Compartilhada .......................................................... $\quad 38$

Satisfação no Trabalho.................................................................... 39

Resumo do Capítulo ........................................................................ 40

3. METHODOLOGIA …....................................................................... 42

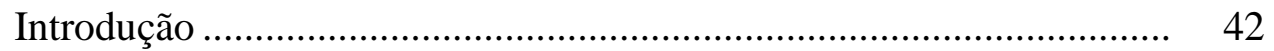

Tipo da Pesquisa ..................................................................... 42

Instrumento da Pesquisa ............................................................ 43

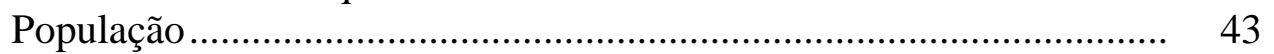

Coleta de Dados ................................................................. 44

Análise dos Dados.......................................................................... 44

Institutional Review Board ............................................................. 44

Resumo do Capítulo....................................................................... 44

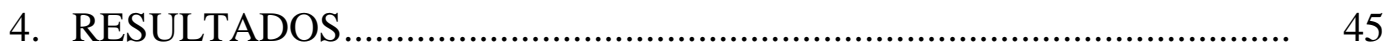

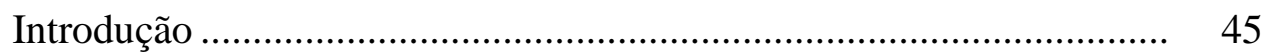

Análise e Apresentação dos Dados .................................................... 46

Análise do Nível de Saúde Organizacional ........................................ 47

Análise das Seis Áreas-Chave de Saúde Organizacional .................... 50

Análise do Estilo de Liderança e do Nível de Saúde

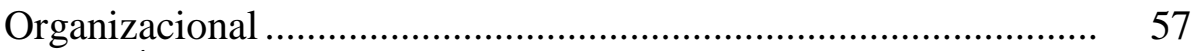

Análise do Índice de Satisfação no Trabalho...................................... 58

Resumo do Capítulo....................................................................... 61

5. CONCLUSÕES E RECOMENDAÇÕES ........................................... 62

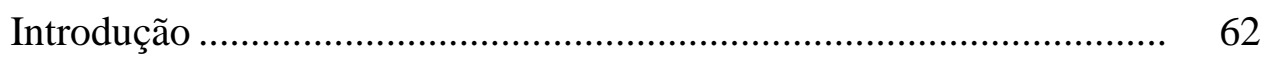

Resumo do Estudo .................................................................. 62

Descobertas .............................................................................. 63

Perguntas e Respostas da Perquisa .............................................. 66

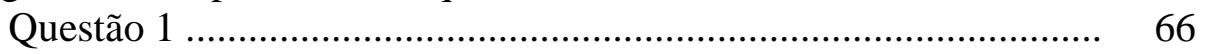

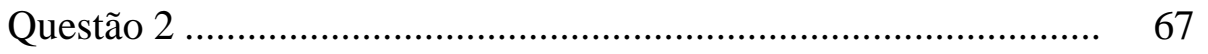



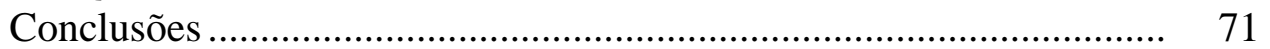

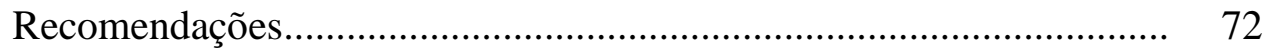

Sugestões para Estudos Posteriores .................................................... 74

Apêndices
A. CARTA DO COMITÊ DE ÉTICA DA ANDREWS
B. RELATÓRIO DA AVALIAÇÃO DA LIDERANÇA
ORGANIZACIONAL (OLA). 
REFERÊNCIAS..

104 


\section{LISTA DE FIGURAS}

1. Nível de Saúde Organizacional da Associação Central Amazonas

2. Nível de Saúde Organizacional das Áreas-Chave da (ACeAm)

Comparado com a Pontuação Média de Todas as Organizações que

Fizeram o OLA

3. Nível de Saúde Organizacional das Áreas-Chave da (ACeAm) por Categoria

4. Comparativo da Percepção dos Participantes com Respeito a

Organização e a Liderança por Categoria

5. Resultado da Satisfação no Trabalho da ACeAm por Categoria 


\section{LISTA DE TABELAS}

1. População e Respondentes

2. População e Respondentes por Categoria .................................................... 46

3. Tabela de Pontuação para Definição do Índice de Saúde

Organizacional

4. Índice e Nível de Saúde Organizacional

5. Índice e Nível de Saúde Organizacional da ACeAm por Categoria

6. Índice de Saúde Organizacional da ACeAm por Área-Chave

7. Ímdice de Saúde Organizacional da ACeAm por Área-Chave e por Categoria

8. Maiores Índices das Áreas-Chaves de Saúde Organizacional da $\mathrm{ACeAm}$

9. Menores Índices das Áreas-chave de Saúde Organizacional da $\mathrm{ACeAm}$

10. Maiores Índices das Áreas-chave de Saúde Organizacional da ACeAm por Categoria.

11. Menores Índices das Áreas-Chave de Saúde Organizacional da ACeAm por Categoria

12. Comparative da Percepção dos Participantes da Média da Organiação e da Liderança.

13. Estilos de Liderança e os Níveis de Saúde Organizacional

14. Índice e Estilo da Liderança da ACeAm.

15. Índices e Estilo de Liderança por Categoria

16. Índice de Satisfação no Trabalho

17. Índice de Satisfação no Trabalho por Categoria 


\section{LISTA DE ABREVIAÇÕES}

ACeAm Associação Central Amazonas

DSA Divisão Sul Americana

IASD Igreja Adventista do Sétimo Dia

OLA Organizational Leadership Assessment 


\section{AGRADECIMENTOS}

Agradeço primeiramente a Deus pela vida e possibilidade de desenvolver minha liderança no contexto da pregação do evangelho.

Agradeço minha amada esposa Cristiane pelo apoio incondicional.

Agradeço minhas amadas filhas Gabriely Karine e Débora Naiara por me apoiarem em todos os momentos.

Agradeço aos meus estimados orientadores Dr. Eliseu e Dr. Josmar pelo incentivo e apoio. 


\section{CAPÍTULO 1}

\section{INTRODUÇÃO}

De acordo com Kouzes e Posner (2013, p. 1) “liderança não é moda”, é um desafio da organização no passado, no presente e no futuro. Em tempos de incerteza, turbulências e desafios, "o único antídoto para o caos, estagnação e desintegração" é a liderança (p. 1). O tempo, problemas, tecnologias e pessoas mudam, mas a liderança continua como a base para a vida e o crescimento das organizações. Burns (1995, p. 9) afirmou que "liderança é um dos mais observados e o menos compreendidos fenômeno na terra" . Assim como a humanidade é antiga, também é antigo o interesse pela tema da liderança (Bergamini, 2009).

Para Covey (2008, p. 29), “a confiança é uma das armas mais poderosas de motivação e inspiração. As pessoas querem que confiemos nelas." Os líderes que trabalham com alta confiança em suas organizações conseguem resultados melhores do que aqueles que trabalham com baixa confiança.

Chiavenato (2014b, p. 123) destaca que "a liderança é necessária em todos os tipos de organização humana, seja nas empresas ou em cada um de seus departamentos. Ela é essencial em todas as funções da administração. O líder precisa conhecer a natureza das pessoas para que possa exercer sua liderança."

De acordo com Collins (2013, p. 5) ele e sua equipe de pesquisadores iniciaram um "trabalho de pesquisa de cinco anos, uma jornada para explorar os mecanismos internos da transformação de uma empresa boa em uma empresa excelente". As empresas selecionadas foram aquelas que deram um salto de 
resultados bons para excelentes e o sustentaram por pelo menos quinze anos depois do momento da transição. Após realizar a pesquisa concluiu que os líderes responsáveis por essa transição tinham humildade pessoal e uma firme vontade profissional que os levaram a colocar as pessoas certas nos lugares certos, enfrentar as dificuldades com uma confiança de que iriam vencer no final, simplificar conceitos complexos em uma ideia básica, fomentar a cultura da disciplina, pois quando há pessoas disciplinadas não precisam de hierarquia e utilizam recursos tecnológicos para acelerar o crescimento. O líder excelente ao que ele considera ser nível cinco, que deseja a continuidade da empresa, por isso dedica grande esforço para escolher e preparar sucessores. Este líder se preocupa mais com a organização do que com sua reputação.

Para Blanchard (2011), a liderança é definida como "a capacidade de influenciar os outros pela liberação de seu poder e potencial para impactar o bem maior" (p. xvi). A liderança de alto nível tem o objetivo certo e a visão certa, trata seus clientes corretamente, trata os funcionários com justiça e exercem o tipo correto de liderança.

Kouzes e Posner (2013) argumentam que os líderes nunca realizam sozinhos coisas extraordinárias. Por isso, liderança é relacionamento. Relacionamento entre aqueles que desejam liderar e aqueles que escolheram seguir. A qualidade deste relacionamento entre líder e liderado é fator crucial quando se trata de realizar coisas extraordinárias. O relacionamento pautado por desconfiança jamais produzirá resultados duradouros. Já o relacionamento pautado pelo respeito e confiança superará adversidades intensas e deixará um legado significativo.

De acordo com Charan (2008) a liderança é um fator importante para as organizações porque gera e aplica a energia das pessoas, lhes proporciona uma direção e sincroniza seus esforços. Uma forte liderança faz com que uma empresa boa 
seja ainda melhor da mesma forma que, uma liderança fraca reduz o seu potencial e, com o tempo, a destrói.

Para Blanchard (2011) liderar em alto nível é um processo de alcançar resultados que valham a pena ao mesmo tempo em que tratamos as pessoas com respeito e consideração, e não servir apenas aos interesses da liderança, o que faz esquecer de agir com justiça, para o bem-estar de todos os envolvidos. Com este modelo a liderança que serve a si mesma não subsistirá. "Líderes que servem a si mesmos serão uma coisa do passado" Blanchard (2011, p. xviii). Hoje precisa-se de líderes que sirvam os liderados e os lidere depois.

De acordo com Lewis e Noble (2015) a liderança servidora é em muitos aspectos uma ideia antiga, mas, ao expressa-la no final do século 20 no contexto do mundo dos negócios, Greenleaf nos apresentou algo como um novo paradigma, e um que, em muitos aspectos, talvez ainda seja contrário às ideias de exercício do poder e gestão de pessoas.

Segundo Greenleaf (2002, p. 13) o líder servo “começa com o sentimento natural de querer servir, servir em primeiro lugar. Então essa escolha consciente leva a pessoa a aspirar liderar”. Há uma diferença significativa entre aquele que quer liderar primeiro e aquele que quer servir primeiro. A diferença manifesta-se no cuidado dispensado pelo líder servo para garantir aos liderados a mais alta prioridade em suprir suas necessidades primeiro que as do líder e da organização.

De acordo com Miguel (2009, p. 49) o conceito da liderança servidora se “opõe diretamente os princípios tradicionais de liderança, cujo paradigma consiste em visualizar o líder como um herói dotado de poder mágico, como alguém em posição de superioridade que impõe ordem aos seus seguidores, subordinados ou dependentes". 
Locke (1976 como citado em Martinez, M. C., \& Paraguay, A. I. B. B., p. 61) define a satisfação no trabalho "como um estado emocional agradável resultante da avaliação que o indivíduo faz de seu trabalho, resultado da percepção da pessoa sobre como o trabalho satisfaz ou permite satisfação de seus valores importantes no trabalho".

De acordo com Robbins (2010) para conseguir alta satisfação no trabalho e diminuição da rotatividade é necessário atrair e contratar pessoas cujos valores pessoais e personalidade sejam compatíveis com os valores e a cultura da empresa. Esse ajuste resultará em satisfação no trabalho, comprometimento com a organização e baixa rotatividade.

\section{Contexto do Estudo}

A Associação Central Amazonas (ACeAm), anteriormente denominada Missão Central Amazonas é uma instituição regional da Igreja Adventista do Sétimo Dia (IASD) que atua no Amazonas desde 1940 quando foi fundada (Seventh-Day Adventist Yearbook, 2014). A partir de 2005 atua na região Central da capital Manaus e na região noroeste do estado. A instituição possui 38.285 membros distribuídos em 203 igrejas organizadas e 130 grupos organizados. De acordo com o Adventist Church Management System (2009) a ACeAm possui 59 pastores , divididos em três grupos, os administradores que são, o Presidente, o Secretário e o Tesoureiro, os Departamentais e os Pastores distritais. O Campo possui uma rede educacional com nove escolas e 3.603 alunos. A ACeAm apresenta um calendário eclesiástico com ações da Divisão Sul Americana (DSA) instituição que administra a igreja em oito países da América do Sul, ações da União Noroeste Brasileira (UNoB) instituição que administra a igreja nos estados do Amazonas, Roraima, Rondônia e 
Acre e soma-se a estas ações várias outras que o Campo (ACeAm) realiza através de seus de seus departamentos.

A administração da ACeAm é composta pelo Presidente que "deve ser um pastor ordenado de experiência e boa reputação" (Manual da Igreja Adventista do Sétimo Dia, 2016, p. 33), um Secretário Executivo e um Tesoureiro. Na categoria de gerentes estão os Departamentais que são pastores ou professores, homens ou mulheres com formação superior geralmente em Teologia ou Pedagogia. Já os Pastores distritais são homens com formação superior que cuidam de uma ou mais igrejas agrupadas em regiões denominadas distritos pastorais.

De acordo com Greenleaf (1998, p. 85), “a essência da liderança é que o líder faça o esforço primeiro. O líder dá o primeiro passo na crença de que, se ele providenciar uma clara demonstração intencional de construir um relacionamento mais honesto, os seguidores responderão". Este modelo é chamado pelo autor de poder como persuasão.

Para Hunter (2006, p. 20) "liderar significa conquistar as pessoas, envolve-las de forma que coloquem seu coração, mente, espírito, criatividade e excelência a serviço de um objetivo. É preciso fazer com que se empenhem ao máximo na missão, dando tudo pela equipe". O modelo de liderança ou gerenciamento orientado para resultados pode colocar as pessoas em posições de liderança, mas não é uma ferramenta eficiente para inspirar os outros a fazerem um bom trabalho.

Conforme Blanchard (1996) o líder do futuro compreendendo que a implementação e a visão são funções da liderança, não ficará defendendo a atual hierarquia tradicional. A consequência desta nova visão é que o líder estará disposto a virar a pirâmide ao contrário para implementar a visão. "Se você trabalha para seu pessoal, seu propósito é ajuda-los a atingir suas metas. A função dos líderes na 
implementação é ajudar as pessoas a vencer, apoiando-as e removendo barreiras a fim de realizarem as metas que farão com que a visão ser torne realidade" (p. 103).

Segundo Covey (2002, p. 171) é preciso acontecer uma mudança no paradigma de como lideramos. A visão do líder deve ser baseada em princípios e ele administra "com justiça, eficiência e eficácia”. Os líderes baseados em princípios procuram tornar tarefas repetitivas e enfadonhas automatizadas. Os liderados são convidados para participar nas decisões, problemas desafiadores, aproveitando assim as capacidades dos recursos humanos. Permitem aos liderados assumir mais autocontrole e auto-direção a medida que se desenvolvem.

Para Covey (2002) a liderança baseada em princípios administra as pessoas através de um conjunto de princípios comprovados. Esses princípios são as leis naturais e os valores sociais que há séculos tem caracterizado toda sociedade e toda civilização responsável. Elas aparecem em forma de valores, ideias, ideais, normas e ensinamentos que elevam, enobrecem, satisfazem, fortalecem e inspiram (p. 171).

\section{Definição do Problema}

A existência de insatisfação por parte de alguns dos pastores distritais e líderes da igreja local da ACeAm com respeito ao excesso de atividades votadas em seu planejamento anual e contidas calendário de atividades, que são executadas por eles.

A insatisfação com o excesso de atividades da Organização pode estar relacionada com a percepção que os pastores tem das práticas e estilos de liderança e do nível de satisfação no trabalho. (Marcon, 2015)

\section{Propósito do Estudo}

O propósito do presente estudo é identificar a percepção dos participantes: os líderes administrativos, os departamentais, e os pastores distritais que trabalham na 
linha de frente, em relação as práticas, os estilos de liderança, o nível de saúde organizacional e a satisfação no trabalho.

\section{Importância do Estudo}

Parte da importância do estudo é identificar qual é a percepção deste grupo para aprimorar as práticas administrativas com o foco na liderança servidora como decorrência da pesquisa.

Este estudo será importante para a elaboração de programas que venham desenvolver as práticas administrativas para solidificar e aprimorar a liderança servidora da ACeAm. Charan (2010) destaca que o líder é responsável pela definição do caminho que a empresa deve seguir, mas é necessário saber executar, pois a execução é que impulsiona a organização por esse caminho, e permite o aproveitamento das oportunidades.

De acordo com Hunter (2006, p. 18) liderança servidora é definida como “a habilidade de influenciar pessoas para trabalharem entusiasticamente visando atingir objetivos comuns, inspirando confiança por meio da força do caráter”.

A liderança ocupa um papel fundamental no crescimento, estagnação ou morte de uma organização. Assim é essencial que a Alta liderança e a Gerência conheçam suas práticas, estilo de liderança, a saúde organizacional e reflitam sobre o que fazer para a organização pesquisada continue crescendo.

\section{Perguntas da Pesquisa}

Diante do contexto do estudo, dos problemas e dos objetivos da investigação anteriormente descritos, o pesquisador propõe que as seguintes perguntas sejam respondidas através da pesquisa: 
1. Qual o nível de Saúde Organizacional da Associação Central Amazonas na percepção da área ministerial?

2. Quais as práticas e estilos de liderança que receberam as maiores e as menores pontuações?

3. Qual o nível de satisfação no trabalho entre os que compõem a força de trabalho deste estudo?

\section{Metodologia}

A presente pesquisa é do tipo quantitativa, cujo método é prático e objetivo (Guerra, 2008), utilizando o instrumento Organizational Leadership Assessment (OLA). Este instrumento desenvolvido por Laub (1999) mede a Saúde Organizacional, as Práticas e Estilos de Liderança, bem como a Satisfação no Trabalho. O Instrumento OLA foi aplicado a uma população de 59 pessoas da ACeAm, sendo 46 deles pastores distritais, aqui denominados Força de Trabalho; 10 departamentais, sendo sete pastores e três mulheres descritos neste estudo como Gerência; e três pastores que são administradores da ACeAm fazendo parte da Alta Liderança. Este instrumento de pesquisa será essencial para auxiliar a perceber qual a saúde organizacional da ACeAm e qual a relação entre o estilo de liderança vigente na atual administração em relação ao conceito de liderança servidora apresentado por (Laub, 1999).

\section{Definição de Termos}

O presente trabalho envolve termos que demandam definição mais detalhada para uma melhor compreensão dos leitores, conforme lista abaixo:

Áreas-chave: São as seis áreas que analisam a Saúde Organizacional através do instrumento OLA. As áreas são: Valorização de Pessoas, Desenvolvimento de 
Pessoas, Construção de Comunidade, Demonstração de Autenticidade, Provisão de Liderança e Liderança Compartilhada.

Associação Central Amazonas (ACeAm): Organização da Igreja Adventista do Sétimo Dia que compreende 203 igrejas organizadas e 130 grupos organizados na região Central de Manaus com 18.999 membros e com 20.339 membros na região noroeste interior do estado do Amazonas.

Campo: Território da ACeAm na região central de Manaus, e o noroeste do Estado, composto por 333 congregações, organizadas em 46 distritos pastorais. Há outra Associação denominada Amazonas Roraima que administra o trabalho na região norte e leste de Manaus e leste do estado do Amazonas e estado de Roraima com 54.000 membros

Departamentais: São homens ou mulheres, com formação de nível superior, geralmente teológica ou pedagógica que atuam como promotores e gerentes de diversas áreas de trabalho na ACeAm, entre os quais estão os departamentos de Evangelismo, Ministério Pessoal e Escola Sabatina, Ministério Jovem, da Família, de Educação, de Publicações, de Comunicação, de Mordomia Cristã, de Mulheres, de Crianças e Adolescentes, Área Feminina da Associação Ministerial e a Secretaria Ministerial.

Distritos Pastorais: Regiões eclesiásticas da ACeAm, as quais possuem um determinado número de congregações, administradas e cuidadas por pastores distritais.

Estilos e Práticas de Liderança: Os estilos de liderança apresentados neste estudo estão divididos em três. São eles: Autocrático, Paternalista e Servidor que nos ajuda a compreender como as organizações diferem quanto à abordagem da liderança, suas percepções sobre a pessoa, e acima de tudo, seu sucesso. 
Igreja Adventista do Sétimo Dia (IASD): É uma igreja cristã mundial organizada em 1863 nos Estados Unidos e que está presente no estado do Amazonas desde que foi fundada em 1927 na cidade de Maués e presente desde 1931 em Manaus.

Saúde Organizacional: Trata-se da maneira como o instrumento de pesquisa OLA considera as práticas e o estilo de liderança de uma organização que é expressa em seis níveis.

Liderança Servidora: O termo Liderança Servidora passou a ser usado depois que Greenleaf (1998) publicou o ensaio O Líder Servidor. A grande e atrativa novidade nesta prática de liderança é que ela deve ser exercida com foco de servir os liderados em vez comandar os postos da organização.

Organizational Leadership Assessment (OLA): Avaliação de Liderança Organizacional, instrumento desenvolvido por Laub (1999) para avaliar a saúde organizacional incluindo o nível de liderança servidora da organização.

Pastores: Este termo foi usado para ser uma referência no texto aos pastores que atuam nas três categorias da ACeAm (Administradores, Departamentais e Distritais), descritos no estudo como: Alta Liderança, A Gerência e a Força de Trabalho.

Pastores Distritais: Este termo refere-se aos pastores que cuidam das igrejas que estão organizadas em distritos, tratados na pesquisa como Força de Trabalho.

Satisfação no Trabalho: É parte das análises verificadas pelo instrumento OLA. Expressão presente nesta pesquisa, pois se trata de parte da essência do trabalho, expressa em três categorias: Precisa Melhorar, Bom e Muito Bom. 


\section{Delimitações do Estudo}

O estudo está delimitado ao território da ACeAm, o qual compreende uma área geográfica que envolve Manaus, região Central da capital do Estado do Amazonas e a região noroeste do interior. A população da pesquisa se restringe à área ministerial da ACeAm incluindo, distritais, departamentais e administradores.

\section{Organização do Estudo}

Este trabalho é composto por cinco capítulos. Sua estrutura é a seguinte:

O Capítulo 1 apresenta a introdução com o contexto da realidade em estudo, a definição do problema, o propósito do estudo e a importância do mesmo. Em seguida apresenta-se as perguntas da pesquisa que levam a uma busca por melhores e maiores resultados. A seguir vem a metodologia, a definição de termos e as delimitações do estudo.

O Capítulo 2 apresenta a revisão de literatura do assunto em estudo e suas respectivas variantes. Apresenta os conceitos de liderança e as principais teorias de liderança, com uma ênfase focada na liderança servidora.

O Capítulo 3 apresenta a metodologia utilizada neste estudo, o tipo de pesquisa e sua população, os procedimentos e a análise de dados.

O Capítulo 4 apresenta os resultados da pesquisa.

O Capítulo 5 apresenta as conclusões do estudo e sua relação com os dados coletados seguidos de recomendações relacionadas à saúde organizacional da ACeAm, e indicações de eventuais estudos posteriores e pertinentes ao tema. 


\section{CAPÍTULO 2}

\section{REVISÃO DE LITERATURA}

\section{Introdução}

A liderança é algo essencial para o ser humano, por isso, "o interesse pela liderança é tão antigo quanto o próprio homem. Bastou apenas que duas pessoas se encontrassem para que uma delas fosse solicitada a interpretar aquilo que deveria estar ocorrendo naquele momento e indicasse algum rumo a ser seguido" (Bergamini, 2009, pg. 1). A revisão de literatura do presente trabalho tem como objetivo analisar a liderança servidora da ACeAm com base numa pesquisa fundamentada no instrumento OLA que mede o nível de saúde organizacional, as práticas, os estilos de liderança e a satisfação no trabalho das instituições. A pesquisa foi aplicada entre os pastores do Campo. Para esta revisão foram consideradas cinco áreas específicas: Conceitos de Liderança, Teoria da Liderança, Estilos de Liderança, Liderança Servidora, as Seis áreas-chave da Saúde Organizacional e da Satisfação no Trabalho.

\section{Conceitos de Liderança}

Na literatura existente sobre liderança pode-se encontrar os mais diversos conceitos emitidos por diversos autores. Bergamini (2009, pág. 2), diz que "o grande interesse pelo tema da liderança determinou o aparecimento de inúmeros conceitos dentre os pesquisadores em comportamento organizacional.” Embora haja inúmeros conceitos, somente dois elementos mostram ser comuns a quase todos. Um refere-se a 
um "fenômeno grupal" e o outro se relaciona com o "processo de influenciação, exercido de forma intencional pelo líder e seus seguidores” (p. 3).

Segundo Charan (2010), o líder é responsável pela definição do caminho que a empresa deve seguir, mas é necessário saber executar, pois a execução é que impulsiona a organização por esse caminho, e permite o aproveitamento das oportunidades. Para que o líder tenha sucesso ele precisa fazer acontecer e acompanhar os três processos chave de uma organização: escolher e desenvolver líderes para o futuro, desenvolver estratégias levando em consideração o ambiente de negócios globais em constante evolução e a elaboração de planos operacionais flexíveis. Charan (2008) apresenta a liderança como um fator importante para as organizações porque gera e aplica a energia das pessoas, lhes proporciona uma direção e sincroniza seus esforços. Uma forte liderança faz com que uma empresa boa seja ainda melhor da mesma forma que, uma liderança fraca reduz o seu potencial e, com o tempo, a destrói.

De acordo com Collins (2013) após realizar uma pesquisa de cinco anos com empresas que eram boas e se tornaram excelentes concluiu que os líderes responsáveis por essa transição fenomenal tinham humildade pessoal e uma firme vontade profissional que os levaram a colocar as pessoas certas nos lugares certos, enfrentar as dificuldades com uma fé inabalável que iriam vencer no final, simplificar conceitos complexos em uma ideia básica, fomentar a cultura da disciplina, pois quando há pessoas disciplinadas não precisam de hierarquia e utilizam recursos tecnológicos para acelerar o crescimento. O líder excelente é caracterizado como nível cinco, que deseja a continuidade da empresa, por isso dedica grande esforço para escolher sucessores. Este líder se preocupa mais com a organização do que com sua reputação. 
Blanchard (2011, p. xvi), define liderança "como a capacidade de influenciar os outros pela liberação de seu poder e potencial para impactar o bem maior”. A liderança de alto nível tem o objetivo certo e a visão certa, tratam seus clientes corretamente, tratam os funcionários com justiça e exercem o tipo certo de liderança.

De acordo com Senge (2014), a palavra líder passou a se referir a uma posição de autoridade onde reside todo o poder da mudança. No Ocidente, os líderes são heróis, grandes homens que se superam em tempos de crise. "A nova visão de liderança nas organizações que aprendem se centra em tarefas mais sutis e mais importantes" Senge (2014, p. 412). Nestas organizações os líderes entendem que a organização é um sistema, onde todos devem participar, líderes e liderados nos processos, na formação de novas estruturas, construção das equipes, formação da visão e propósitos da organização.

Segundo Covey (2005, p. 21) “a maioria das organizações com problemas desenvolveu uma cegueira funcional em relação aos seus defeitos. Elas sofrem não porque não podem resolver seus problemas, mas porque não podem vê-los". Assim o oitavo hábito é um tipo de liderança que comunica às pessoas seu valor e potencial de forma tão clara que elas mesmas passam a enxergá-los. Para isso, é preciso ouvir as pessoas, envolve-las e afirma-las por meio de palavras e dos Quatro Papeis do Líder. O primeiro papel é modelar pessoas e equipes inspirando a confiança a partir da confiabilidade. O segundo é descobrir caminhos, criando ordem sem exigi-la, envolvendo as pessoas em decisões estratégicas, especialmente no que se refere a valores e objetivos de alta prioridade, gerando conexão emocional. O terceiro é alinhar estruturas, sistemas e processos aumentando o espírito de confiança. O quarto é liberar o potencial humano sem motivação externa. 
Kellerman (2012), diz que ser líder tornou-se um mantra. É um suposto caminho para o adquirir dinheiro e o poder, um meio para a realização tanto individual como institucional e um mecanismo para, as vezes, criar mudanças que nem sempre serão para o bem comum. Porém, ao analisar a liderança hoje percebe-se uma mudança profunda e rápida com respeito a este conceito atual, porque o poder de influência está sendo transferido de cima para baixo, os que estão no topo com menos poder e influência; os que estão do meio para baixo, com mais. Os seguidores tem um senso de direito ampliado, exigem mais e dão menos.

Kouzes e Posner (2013) destacam que os líderes nunca realizam sozinhos coisas extraordinárias. Por isso, liderança é relacionamento. Relacionamento entre aqueles que desejam liderar e aqueles que escolheram seguir. A qualidade deste relacionamento entre líder e liderado é fator crucial quando se trata de realizar coisas extraordinárias. O relacionamento pautado por desconfiança jamais produzirá resultados duradouros. Já o relacionamento pautado pelo respeito e confiança superará adversidades intensas e deixará um legado significativo.

Para Bowditch (1992, citado em Lisboa (2006), T. C., p. 167) a liderança é como "um processo de influência, geralmente de uma pessoa para outra, na qual o indivíduo ou grupo é orientado para o estabelecimento e a conquista de metas". Segundo Lisboa (2006, p. 168) os líderes precisam “saber e conhecer o que energiza o comportamento das pessoas, como o comportamento das pessoas é dirigido e como alguns tipos de comportamento são sustentados ou mantidos”. O líder pode influenciar grandemente na motivação deles gerando satisfação e produzindo resultados.

De acordo com Alaby (2006, p. 29) “o novo líder é flexível. É como a água, que, independentemente do estado e forma que ocupa, preserva sua essência. Como a 
água, o precioso líquido indispensável à vida, os líderes não podem mudar a sua essência, mas na sua experiência, podem ser flexíveis".

Whamond (2012) comenta que para ser um líder há apenas uma exigência: ter seguidores. Um seguidor é alguém que voluntariamente vai na direção do líder que o inspira. A responsabilidade da liderança não é tomada, ela é dada. Somente quando outros escolhem nos seguir é que podemos liderar verdadeiramente. A base de um grande líder é o seu caráter. O caráter deve revelar honestidade, humildade, honra e disposição.

Chiavenato (2014b, p. 123) destaca que "a liderança é necessária em todos os tipos de organização humana, seja nas empresas ou em cada um de seus departamentos. Ela é essencial em todas as funções da administração. O líder precisa conhecer a natureza das pessoas para que possa exercer sua liderança."

\section{Estilos de Liderança}

Os estudos sobre os estilos de liderança demonstram os diversos tipos de ações realizadas pelos líderes, a reação dos liderados e como o ambiente influencia o uso de determinado estilo.

Para Chiavenato (2014b, p. 126), a "a abordagem dos traços se refere aquilo que o líder é, a abordagens dos estilos de liderança se refere àquilo que o líder faz, isto é, seu estilo de comportamento para liderar. A teoria mais conhecida refere-se a três estilos de liderança: autoritária, liberal e democrática”. Chemers (1995, citado em Marinho (2006), R. M., p. 12), explica que depois da teoria dos Traços “o enfoque mudou dos traços de personalidade para os comportamentos do líder, dando origem, entre outros, a três estilos básicos de liderança. O estilo autocrático, o democrático e o laissez-faire". 
Goleman (2015), descreveu seis estilos de liderança diferentes que os líderes usam para motivar as pessoas, que são: visionário, conselheiro (coaching), agregador (afiliativo), democrático, modelo (marcador de rítimo) e autoritário.

\section{Liderança Autoritária}

Para Chiavenato (2014c, p. 440), a liderança autoritária "toma as decisões e impõe suas ordens ao grupo". Ele apresenta o resultado de uma pesquisa realizada com um grupo cuja liderança autoritária foi exercida e os resultados no grupo foram, “tensão, frustração e agressividade”, ausência de espontaneidade, iniciativa ou formação de grupos por amizade. Soma-se a isso, falta de satisfação no trabalho e não realização das tarefas na ausência do líder.

Segundo Marinho (2006) o líder autoritário controla o grupo, as atividades e centraliza em si as decisões.

Para Murray (2011), este modelo é o mais utilizado e geralmente o menos eficaz. Por usar a critica e raramente elogios ele pode enfraquecer o moral e a satisfação no trabalho. Ainda assim, em situações de crise, quando mudanças urgentes são necessárias, essa pode ser uma abordagem muito eficaz.

De acordo com Goleman (2015) o estilo do autoritarismo ou coercitivo dentre todos os estilos é o menos eficaz na maioria das situações. O estilo é o que faz o clima organizacional, e neste caso a flexibilidade é a mais atingida. A tomada de decisão centrada no líder mata as novas ideias na raiz. Os liderados se sentem desrespeitados, o senso de responsabilidade diminui, inibe-se da iniciativa própria, além de gerar certo espírito de rebelião. 


\section{Liderança Liberal}

Segundo Chiavenato (2014b, p. 126), “o líder liberal delega totalmente as decisões ao grupo e o deixa-o completamente à vontade sem controle algum. Embora a atividade dos grupos fosse intensa, a produção foi medíocre". O individualismo se fortaleceu e diminuiu o respeito pelo líder.

Para Marinho (2006, p. 12) o estilo liberal também conhecido como laissezfaire, envolve "um baixo nível de qualquer tipo de atividade exercida pelo líder, cabendo assim a cada liderado a iniciativa, a decisão e responsabilidade das atividades".

\section{Liderança Democrática}

Segundo Chiavenato (2014c), no estilo democrático o líder conduz, orienta e incentiva a participação democrática. Como resultado da pesquisa houve a formação grupos de amizade e relacionamentos cordiais entre os trabalhadores. A comunicação entre líderes e liderados era espontânea, franca e cordial. Na ausência do líder o trabalho continuava em ritmo seguro. Soma-se a isso, comprometimento, responsabilidade, integração grupal e satisfação no trabalho.

Marinho (2006), comenta que um estudo clássico, conduzido por Kurt Lewin, concluiu que o estilo democrático parecia ser o mais eficaz do que os estilos autocrático e permissivo comparados nas atividades que envolviam as pessoas da pesquisa.

De acordo com Murray (2011) este estilo se apoia no conhecimento e nas habilidades das pessoas e gera um compromisso do grupo com os objetivos pretendidos.

Para Goleman (2015) o líder democrático ouve ideias dos liderados, obtém adesão, desenvolve confiança, respeito e compromisso. Ao permitir que o trabalhador 
tenha influência nas decisões que afetam suas metas e como realizam o trabalho, o líder aumenta a flexibilidade e a responsabilidade.

\section{Liderança Visionária}

Para Goleman (2015) o estilo de liderança visionária é importante quando uma organização precisa de um novo direcionamento. O objetivo é levar as pessoas para um novo conjunto de sonhos compartilhados. Este líder motiva as pessoas e esclarece como o trabalho delas se enquadra numa visão maior da organização. Este estilo estabelece o fim, ou seja, onde a organização precisa chegar, mas geralmente oferece liberdade para as pessoas criarem seus próprios meios para conquistar o objetivo. Os liderados tem liberdade para inovar, experimentar coisas novas e correr riscos.

\section{Liderança Conselheira}

Goleman (2015) considera que este estilo foca o contato individual, mostrando como melhorar o desempenho e ajuda cada um a conectar os objetivos de cada um com os objetivos da organização. Quando o empregado deseja um desenvolvimento profissional este estilo funciona melhor. Neste estilo o grande destaque é a capacidade de delegar. Se o empregado interpretar os conselhos como controle individual o efeito será negativo, pois acontecerá a perda de confiança.

\section{Liderança Agregadora}

Para Goleman (2015) este estilo enfatiza o trabalho em equipe, criando harmonia em grupo, conectando as pessoas entre si e colocando as pessoas em primeiro lugar. Os líderes valorizam os indivíduos e suas emoções. O líder agregador é mestre em desenvolver uma sensação de pertencimento. Este estilo é valioso para melhorar a harmonia da equipe, aumentar o moral, corrigir problemas de comunicação ou restaurar a confiança em uma organização. 


\section{Liderança Modelar}

Goleman (2015) afirma que este estilo estabelece elevados padrões de desempenho, pois o modelo a ser seguido é o próprio líder. Este líder tem o intuito de fazer as coisas acontecerem de forma rápida e melhor, e solicita o mesmo dos liderados. No entanto este estilo deve ser utilizado moderadamente, pois pode enfraquecer o moral e fazer as pessoas sentirem que estão fracassando.

\section{Teorias de Liderança}

"Várias teorias de liderança caracterizam diferentes escolas de pensamento sobre o tema ao longo da história" (Marinho, 2006, p. 11).

Wheatley (2006), escreveu que os líderes modernos buscam satisfação e propósito para sua liderança. Para Charan (2008), os líderes são diferentes da maioria das pessoas em alguns aspectos que nem mesmo um grande volume de aulas e instrução é capaz de desenvolver. Os líderes pensam e agem de maneira diferenciada. Nesta revisão será analisada as principais teorias de liderança desenvolvidas ao longo dos anos.

As principais teorias de liderança são a Teoria dos Traços de Personalidade, Teoria dos Estilos, Teoria Contingencial, Teoria Transformacional.

\section{Teoria dos Traços de Personalidade}

Para Chiavenato (2014b, p. 125), "a teoria dos traços de personalidade são as mais antigas a respeito da liderança. Um traço é uma qualidade ou característica distintiva da personalidade. Segundo estas teorias, o líder é aquele que tem alguns traços específicos de personalidade que o distinguem da maioria”. De acordo com Chiavenato (2014b) alguns traços característicos da personalidade que definem o líder são: 
Físicos: energia, aparência pessoal, estatura e peso. Intelectuais: adaptabilidade, agressividade, entusiasmo e autoconfiança. Sociais: cooperação, habilidades interpessoais e habilidade administrativa. Relacionados com a tarefa: impulso de realização, persistência e iniciativa. (p. 125).

Para Bergamini (2009), os estudos sobre traços de personalidade procuraram descrever uma espécie de retrato daqueles líderes considerados adequados para situações específicas. Essa teoria enfatiza algumas qualidades pessoais que tipificam o modelo dos bons líderes. Esse pressuposto, supõe que os líderes já nascem como tais, não havendo necessidades de fabricá-los, através de técnicas e treinamentos.

Migueles e Zanini (2009) afirmam que esta teoria configurava a tentativa científica de etiquetar o indivíduo segundo um conjunto de traços padrões/inatos, explicando que a existência destas pessoas que detêm o poder de influenciar outros indivíduos organizados em grupos pequenos ou grandes.

\section{Teoria dos Estilos de Liderança}

Segundo Migueles e Zanini (2009) a teoria dos traços de personalidade foi substituída pela dos estilos de liderança nascida dos estudos de Lewin, Lippit e White.

Para Bergamini (2009), a teoria dos traços foi considerada ultrapassada pois se encontrava os mesmos traços em líderes eficazes, mas também em executivos que não ocupavam cargos que exigissem este tipo de desempenho. Esta mudança de enfoque aconteceu nos EUA na década de 40, pois foi salientado que a melhor forma de liderar residia em um estilo de liderança democrático.

Segundo Chiavenato (2014b, p. 126), a teoria dos estilos de liderança “estudam a liderança em termos de estilos de comportamento do líder em relação aos seus subordinados. Enquanto a abordagem dos traços se refere àquilo que o líder é, a abordagem dos estilos de liderança se refere aquilo que o líder faz, isto é, seu estilo de 
comportamento para liderar. A teoria mais conhecida refere-se a três estilos de liderança: autoritária, liberal e democrática".

Para Migueles e Zanini (2009), dos três estilos de liderança, democrático, autoritário e laissez-faire, o estilo democrático revelou-se como aquele que produziu os melhores resultados quantitativos, qualitativos, de motivação e de satisfação pessoal.

Teoria da Liderança Contingencial ou Situacional

Segundo Bergamini (2009), na teoria contingencial diferentemente dos outros estudos, são os valores grupais que a partir de agora, irão influenciar como importantes determinadas características de personalidade do líder. Essas características são consideradas favoráveis a um tipo de conduta que o grupo considera como uma reação compensadora oferecida pelo líder. Nesta teoria acontece uma troca, a empresa cuida das necessidades básicas e extrínsecas de seus funcionários e o líder cuida daquelas de natureza intrínsecas, como reconhecimento pessoal, aproveitamento do potencial e a auto-realização.

Para Migueles e Zanini (2009), com a decadência da teoria dos estilos aconteceu o aparecimento das teorias contingenciais que propuseram a explicação do fenômeno a partir de variáveis externas que condicionam o comportamento dos líderes.

Segundo Chiavenato (2014b), o conceito de Skinner enfatiza que a teoria de contingência, envolve elementos ambientais, comportamentais e consequências. $\mathrm{O}$ comportamento atua sobre o ambiente para produzir uma determinada consequência. O comportamento pode ser mantido, reforçado, alterado ou suprimido de acordo com as consequências produzidas. Portanto, o comportamento é função de suas 
consequências. $\mathrm{O}$ foco desta teoria é eminentemente externo, pois, enfatiza-se o efeito das consequências ambientais sobre o comportamento e o objetivo das pessoas.

Chiavenato (2014b) destaca que na teoria contingencial o líder precisa ler e interpretar cada situação e definir o estilo mais adequado com o objetivo de alcançar expectativas e objetivos e oferecer resultados não somente para a organização mas também para os envolvidos e para ele próprio.

\section{Teoria Transformacional}

De acordo com Burns (1978, como citado em Vizeu, 2011, p. 57), "o modelo transformacional é centrado na suposição de que a liderança é um fenômeno dual - ou seja, se explica necessariamente pela relação entre líder e liderados, e não apenas pelo entendimento do comportamento dos líderes”. Não foi por acaso que Burns (1978, como citado em Vizeu, 2011, p. 62), "se inspirou nos grandes estadistas que, envolvidos em contextos de liderança que afloraram em momentos históricos graves, conduziram seu próprio grupo de referência na defesa de seus valores fundamentais, aqueles que representavam base cultural de sua própria sociedade”.

O autor afirma: "liderança transformacional ocorre quando uma ou mais pessoas se envolvem uns com os outros, de tal maneira que os líderes e seguidores motivam uns aos outros a níveis mais elevados de motivação e moralidade" (Burns, 1978, p. 20).

Segundo Bergamini (2009), a liderança transformacional é uma das formas mais potentes e duradouras de liderança e é reconhecida como sendo mais bemsucedida quando o "foco é levar o seguidor a transcender seus próprios interesses para benefício da equipe, da organização e dos demais grupos que trabalham em conjunto com ele, para conseguir um objetivo comum" (p. 161). 


\section{Liderança Paternalista}

Para Laub (1999) o estilo paternalista pode ser negativo ou positivo e é considerado por ele no instrumento de pesquisa OLA. Este estilo reflete o nível moderado de saúde organizacional, sendo necessário melhorar nas seis áreas-chave para atingir saúde máxima quando o estilo de liderança servidora for implantado na organização e percebido pelos colaboradores.

Para Behrens (2010) “a liderança paternalista relaciona o papel do gestor com proteção, amizade e familiaridade. O papel do gestor paternalista tem como meta lutar pelos seus colaboradores, principalmente, quando estes estiverem vulneráveis, mas, cuidar um do outro não significa confundir a relação, principalmente, em um país como o Brasil onde a hierarquia é uma característica tão presente na sociedade”.

De acordo com Tortorette (2010) "quando se trata da preferência entre os próprios colaboradores, é inegável que o líder paternalista é sempre o mais almejado, por causa de seu perfil mais tranquilo e conciliador. O líder paternalista é permissivo, conciliador, paciente e tolerante em todas as situações, preocupa-se com o bem-estar do grupo e em não magoar os colaboradores, tenta criar na área um clima cooperativo e de família, é afetuoso e expressa reconhecimento, mas tem dificuldades para punir”.

\section{Liderança Servidora}

O conceito da liderança servidora é revolucionário pois considera o papel do líder fundamental para a organização, mas também importante para a vida, realização e satisfação de cada liderado.

Segundo Spears (1998) foi a partir de 1970, que Greenleaf começou a escrever sobre o tema de liderança servidora.

Segundo Wilkes (1999, p. 251) foi em 1970 que Greenleaf apresentou ao mundo que um novo princípio moral surgia na sociedade. Ele escreveu que as pessoas 
não aceitariam a autoridade das instituições existentes. Para Greenleaf as pessoas “responderão livremente apenas aos indivíduos escolhidos como líderes, por terem sido provados e se mostrado dignos de confiança como servos. No futuro, as únicas instituições viáveis serão aquelas predominantemente dirigidas por servos”.

Spears (1998) destaca que Greenleaf acreditava que cuidar de pessoas, os mais capazes e os menos capazes servindo uns aos outros, é o que faria uma boa sociedade. Para ser construída uma sociedade melhor, mais justa e mais solidária e proporcionar oportunidades para as pessoas crescerem, a forma mais eficaz e econômica e apoiar a ordem social, é necessário elevar a performance de servir de quantas instituiçõos for possível criando novas forças voluntárias regenerativas iniciando com eles um compromisso individual de servir.

Para Blanchard (2011) liderar em alto nível não foca apenas a realização dos objetivos, mas é preciso pensar no "bem maior”, aquilo que é melhor para todos os envolvidos, porque a liderança é um chamado superior. "Liderar em alto nível é um processo de alcançar resultados que valham a pena ao mesmo tempo em que tratamos as pessoas com respeito, consideração a eles e não aos interesses daqueles a quem deveriam servir, por isso esquecem de agir com e justiça, para o bem-estar de todos os envolvidos" Blanchard (2011, p. xvii). Com este modelo a liderança que serve a si mesma não subsistirá. "Líderes que servem a si mesmos pensam que liderança diz respeito apenas a eles, e não aos interesses daqueles a quem deveriam servir” Blanchard (2011, p. xvii). Líderes que servem a si mesmos serão uma coisa do passado, hoje precisa-se de líderes que sirvam os liderados e os lidera depois.

Senge (2014) afirma que a palavra líder passou a se referir a uma posição de autoridade, mas o verdadeiro líder é aquele em quem seus liderados confiam. Esta confiança é resultado de uma demonstração sincera por parte do líder pelo bem estar 
do liderado. A ideia de líderes que servem àqueles que lideram pode parecer idealista, mas é muito pragmática. Para Senge (2014, p. 509) "ser líder é ser guia que significa servir a um objetivo maior".

Segundo Collins (2013, p. 37) a liderança que articulou a transição de empresas boas para excelentes, foram classificados como líderes nível 5. Estes líderes aliaram duas características, "extrema humildade pessoal e uma firme vontade profissional”. Ele define que a humildade pessoal canaliza sua ambição para a empresa, não para si mesmo. Por isso prepara seus sucessores para um êxito maior ainda que o dele, na geração seguinte. Na vontade profissional estabelece o padrão para construir um empresa excelente e duradoura e não investe em nada menos do que isso.

Lewis e Noble (2015) afirmam que a liderança servidora é em muitos aspectos uma ideia antiga, mas, ao expressa-la no final do século 20 no contexto do mundo dos negócios, Greenleaf nos apresentou algo como um novo paradigma, e um que, em muitos aspectos, talvez ainda seja contrário às ideias de exercício do poder e gestão de pessoas.

Para Greenleaf (2002) é possível fundir o papel de servo e o de líder e ainda assim viver e ser produtivo no mundo real. Sendo assim, mais servidores deveriam emergir, como líderes e os liderados deveriam seguir somente líderes servidores. O líder servidor se preocupa em se assegurar de que as necessidades de mais alta prioridade das outras pessoas estão sendo atendidas.

Para Marinho (2006, p. 21) “ser líder significa ser uma pessoa a serviço de outras, tendo como satisfação pessoal e satisfação dos companheiros, vendo no crescimento e progresso dos seus seguidores o seu próprio progresso e crescimento, e, no bem-estar de cada um, o seu próprio bem-estar". 
Segundo Covey (2008) a confiança é uma maneira poderosa de impulsionar, motivar e inspirar as pessoas. Quando confiamos nas pessoas, a reação é positiva. A confiança é essencial para estabelecer relacionamentos eficazes e também conquistar resultados.

De acordo com Hunter (2006, p. 18) liderança servidora é definida como "a habilidade de influenciar pessoas para trabalharem entusiasticamente visando atingir objetivos comuns, inspirando confiança por meio da força do caráter”.. Para Hunter (2006, p. 30) “o líder servidor é autocrático quando se trata de determinados aspectos da organização, como a missão, valores, padrões e responsabilidades. ... Entre as obrigações de uma liderança servidora estão a definição da missão, das normas de comportamento e a indicação de responsabilidades". A liderança pode ser baseada no poder ou na autoridade. A liderança baseada no poder consegue resultados por causa da posição e da capacidade de obrigar. A liderança servidora é baseada na autoridade, sendo uma habilidade de levar voluntariamente os outros a fazerem algo. A autoridade está relacionada com a essência da pessoa e ligada ao seu caráter.

De acordo com Hunter (2006, p. 42) "Jesus faz uma declaração definitiva sobre liderança. A passagem foi interpretada de várias maneiras, mas o fundamental é que Ele diz que qualquer que deseje ser o líder deve primeiro servir. Se você quer liderar, deve servir". "Jesus falava sobre liderar com autoridade, em resumo se alguém quisesse influenciar pessoas, devia servir, ou seja sacrificar-se e procurar o bem maior dos liderados" (p. 42).

Para Blanchard (2011) a definição de líderes servidores é:

Líderes servidores, por outro lado, entendem que seu papel é ajudar as pessoas a alcançarem suas metas. Estão constantemente tentando descobrir o que seu pessoal precisa para ter um bom desempenho e para colocar a visão em prática. Em vez de quererem que os colaboradores agradem seus chefes, líderes servidores querem fazer a diferença na vida dos colaboradores, e, além disso, causar um 
impacto positivo na organização. Com sua ênfase em trazer à tona a grandeza que existe dentro das pessoas. (p. 246).

De acordo com Blanchard (2011) líderes servidores pensam diferente dos autosservidores. O líder autosservidor tem o coração motivado pelo egoísmo, focado em ganhar dinheiro, ou em seu próprio poder, buscando reconhecimento e status. Liderança servidora é um modo de vida para aqueles que tem um coração servidor. Em organizações cujos líderes são servidores, a liderança servidora se torna uma imposição, não uma escolha. Os subprotudos da liderança servidora são uma melhor liderança, melhores serviços, uma organização de alto desempenho, mais sucesso e significado.

\section{As Seis Áreas-Chave da Saúde Organizacional}

Laub (1999) elaborou a pesquisa de OLA, que verifica o nível da saúde da organização tendo como base a liderança servidora. A pesquisa esta fundamentada em seis áreas da saúde organizacional. As áreas chave são: valorização de pessoas, demonstração de autenticidade, desenvolvimento de pessoas, construção de comunidade, provisão de liderança e liderança compartilhada.

De acordo com Hunter (2006) o líder servidor tem como prioridade para com os liderados em "identificar e atender suas necessidades legítimas para que possam se tornar mais eficazes na realização de sua missão" (p.30). Quando alguém se propões a ser líder ter altruísmo é indispensável para atender as necessidades dos outros através do serviço e da disposição de se sacrificar pelos outros se necessário for.

Ainda para Hunter (2006, pp.16-17) “o maior indicador de saúde ou doença organizacional está na liderança ou em sua ausência. Tenho observado que existe uma semelhança entre empresas saudáveis e empresas doentes, casamentos saudáveis e 
casamentos doentes, igrejas saudáveis e igrejas doentes. E a semelhança está na liderança”.

\section{Valorização de Pessoas}

Kouzes e Posner (2013) afirmam que prestar atenção, personalizar o reconhecimento e valorizar os outros de maneira criativa e proativa aumentam a confiança deles no líder. Esse tipo de relacionamento torna-se ainda mais importante à medida que o pessoal das organizações fica cada vez mais global e diversificado. Quando os outros sabem que você, autenticamente, se preocupa com eles, é mais provável que também eles se importem com você.

De acordo com Chiavenato (2014a)

as pessoas constituem o principal ativo da organização. Daí, a necessidade de tornar as organizações mais conscientes e atentas para seus funcionários. As organizações bem sucedidas estão percebendo que para crescer, prosperar e manter sua continuidade será possível se forem capazes de otimizar o retorno sobre os investimentos de todos os parceiros, principalmente investimento nos funcionários. (p. 11).

Segundo Lisboa (2006, p. 169) "a hierarquia das necessidades desenvolvida por Abraham Maslow, apresenta a identificação de um conjunto de impulsos denominado necessidades. Agrupou as necessidades em níveis hierárquicos, cujo grau de importância influencia o comportamento humano”. As necessidades são: necessidades fisiológicas, segurança, sociais e de auto-realização, Para valorizar as pessoas é necessário atender estas necessidades.

Segundo Covey (2005) as empresas deixam de tirar partido dos grandes talentos, engenhosidade e criatividade de seus colaboradores e nunca se tornam organizações verdadeiramente grandes e duradouras porque seus colaboradores não se sentem satisfeitos e valorizados. Assim os líderes precisam entender que a realidade fundamental é que os seres humanos não são coisas para serem controladas. 
Segundo Wheatley (2006, p. 35) "a teoria da motivação, a nossa atenção está se deslocando da busca de recompensas externas para a valorização dos motivadores intrínsecos que nos dão mais energia. Estamos voltando a nos concentrar em nosso profundo anseio por comunhão, de significado, de dignidade, de propósito e de amor na vida organizacional".

Para Wheatley (2006, p. 36) “à medida que deixamos para trás o modelo mecanicista das organizações, e a ideia de trabalhadores como engrenagens substituíveis do maquinário de produção, começamos a ver a nós mesmos em dimensões mais ricas, a apreciar a totalidade que somos e, quem sabe, a planejar organizações que honrem e façam uso dessa grande dádiva que é aquilo que, na qualidade de seres humanos, todos nós somos".

Para Covey (2005) é necessário compreender o paradigma completo de quem somos, uma visão fundamental do ser humano. Há quatro dimensões da pessoa integral, mente, corpo, coração e espírito. Tais dimensões representam as quatro necessidades e motivação básicas de todas as pessoas que são: viver, amar, aprender e deixar um legado. Somente alguém que é respeitado como uma pessoa integral num emprego completo - aquela que recebe pagamento justo, é bem tratada, é usada criativamente e tem oportunidades de atender necessidades humanas com princípios estarão dispostos a fazer as engajar-se nos três níveis superiores das escolhas, que são: da cooperação animada, da dedicação profunda e a empolgação criativa.

De acordo com Teixeira (2012) se a pessoa estiver fazendo o que gosta, de acordo com os seus princípios, num lugar onde é respeitado, se sente valorizado e ainda ganha bem, deixará a empresa extrair tudo o que de melhor o colaborador pode oferecer. 


\section{Desenvolvimento de Pessoas}

Segundo Charan (2008, p. 1) "em todos os níveis, as empresas não tem quantidade nem qualidade suficiente de líderes dos quais precisam”. Os talentos brutos estão presentes nas organizações, quando as empresas souberem como identificar e desenvolver poderão solucionar o problema da falta de liderança. As pessoas com talento para a liderança precisam ser desenvolvidas. Quando lhes permitimos desenvolver competências essenciais e adquirir novas, além de confiar novos trabalhos e dar feedbacks quando é oportuno aceleramos o crescimento no desenvolvimento dos novos líderes.

Kotter (2013) afirma que colocar as pessoas em primeiro lugar, torna-as gratas dentro e fora do ambiente de trabalho. A capacitação dos funcionários é essencial para se colocar em prática as novas visões da organização. Além disso, é necessário treinamento técnico, mas também treinamento de atitude.

Segundo Robbins (2010), as empresas investem bilhões em treinamentos formais porque os funcionários precisam aprender novas habilidades, pois eles não permanecem competentes para sempre. Além disso as habilidades se deterioram e podem se tornar obsoletas.

Para Charan (2007, p. 95) "um sinal evidente de know-how para selecionar e formar líderes é que você deixa a organização mais forte, em relação a concorrência, do que ela estava antes de você assumir". De acordo com Charan (2007) no processo de desenvolvimento de pessoas além de abrir caminho e identificar o que precisam para desempenhar a função atual é necessário diálogo direto e aberto com os líderes em desenvolvimento sobre o que está funcionando e o que não está. O temor da reação deles não pode impedir estas conversas cruciais, pois, é essencial para o desenvolvimento deles. 
Para Aquino (1980), a função do desenvolvimento dos funcionários pelo treinamento, planejamento de carreira e pela promoção são instrumentos responsáveis pelo combate da obsolescência do empregado e da empresa. Funciona também como fatores de motivação, pois possibilita a ascensão funcional e hierárquica.

Segundo Charan (2007) os responsáveis pelo desenvolvimento de pessoas precisam conhecer bem a pessoa, mas também estar certos de que entende o que o cargo requer para que o profissional tenha êxito nele. Se falhar em alguns destes pontos o resultado será mediocridade para a empresa e insatisfação para o profissional.

De acordo com Charan (2008, p. 3) o modelo de aprendizagem eficaz para o desenvolvimento de pessoas deve ter como base: prática, feedback, correções e mais prática. Neste modelo é criada a oportunidade de "proporcionar a cada líder promissor as oportunidades corretas para que se desenvolva no mais rápido num ritmo de crescimento possível, definindo o aprendizado necessário para cada nova atribuição e certificando-se de que o aprendizado de fato ocorreu antes de ajudar o líder a dar o próximo passo". Antes do processo começar é necessário conhecer quais são os verdadeiros talentos do líder.

De acordo com Charan e Conaty (2011) se as empresas administrassem o dinheiro com a mesma negligência que administram seu pessoal, a maioria quebraria. Muitas empresas controlam com muito cuidado suas finanças, porém, não possuem qualquer processo comparável para desenvolver seus líderes nem identificar quais devem ser desenvolvidos

Brandão (2013, p. 76) afirma que "identificar, manter e desenvolver recursos humanos estratégicos é vital para as organizações buscarem resultados significativos e sustentáveis ao longo do tempo." Para Brandão (2013), um programa de treinamento 
deve ter cinco fases. A primeira fase é diagnosticar precisamente a necessidade. A segunda é o desenho do programa de treinamento em si e das condições para a sua aplicação. Na terceira fase, temos a execução do programa. A quarta fase é da avaliação que indica ou não revisões futuras. Já a quinta fase identifica-se a melhor época para a realização do programa de treinamento levando em conta a disponibilidade dos funcionários e os aspectos financeiros.

\section{Construção de Comunidade}

De acordo com Robbins (2015) para qualquer gestor ter sucesso há um ingrediente essencial que é a habilidade interpessoal, ou habilidade para se lidar com gente. As habilidades técnicas podem ser uma qualificação para um emprego, mas raramente são suficientes. Ter habilidades interpessoais competentes é cada vez mais essencial para decidir sobre que pessoas devemos contratar, reter e promover.

De acordo com Marinho (2006, p. 55) “em todas as listas de competências de liderança, o trabalho em equipe é unanimidade absoluta. Ninguém discorda que o líder deve saber trabalhar em equipe". O importante não é "saber algo ou fazer algo, mas a competência de ser alguém diferente, alguém que vive em equipe e quem tem um caso de amor com a sua equipe". Como a liderança envolve relacionamentos, a qualidade da liderança é determinada pelo nível de amor verdadeiro e amizade entre os membros da equipe e da organização.

Segundo Robbins (2015, p.182) “as equipes eficazes não são nem muito pequenas (menos de quatro pessoas) nem muito grandes (mais de uma dúzia de componentes). As equipes pequenas demais tendem a carecer de diversidade de pontos de vista, enquanto as com mais de 12 membros tem dificuldade de execução do trabalho". Quando as equipes são compostas por pessoas flexíveis tem maior capacidade de executar as tarefas uns dos outros. Essa é uma vantagem clara para uma 
equipe porque melhora consideravelmente a capacidade de adaptação e faz com que a equipe seja menos dependente de uma única pessoa.

De acordo com Goleman (2015) a liderança eficaz revela três tipos de empatia. A empatia cognitiva que permite ao líder entender a perspectiva da outra pessoa, os modelos mentais pelos quais esta vê o seu mundo. Isso ajuda o líder expressar uma mensagem que farão sentido a pessoa, por isso o líder se torna mais persuasivo. A empatia emocional, permite ao líder saber como a pessoa se sente naquele momento. Essa habilidade permite ao líder interagir intimamente no nível sentimental aumentando a profundidade da conexão, confiança e compreensão. A terceira é a preocupação empática, onde o líder revela que necessita dos que estão a sua volta. Isso cria uma atmosfera de segurança, confiança e apoio, na qual os subordinados diretos se sentem seguros para correr riscos e explorar novas possibilidades. Quando o líder está do lado, os liderados agem com mais confiança.

De acordo com Covey (2008, p. 29) “a confiança é uma das formas mais poderosas de motivação e inspiração. As pessoas querem que confiemos nelas. Elas reagem positivamente a isso". Para que o líder consiga a confiança de seus liderados é necessário saber que ela está fundamentada em duas qualidades: caráter e competência.

De acordo com Kotter (2013) dispor de um grupo de pessoas certas é condição necessária, mas não suficiente. Também é essencial que a equipe trabalhe bem e de forma integrada. Para que isso aconteça a questão fundamental parece ser a confiança. Em um ambiente de mudanças intensas, em ritmo cada vez mais rápido, a desconfiança entre os membros das equipes se torna um peso colossal. Num ambiente de baixa confiança as pessoas pensarão primeiro em si mesmas e em seus subgrupos, estarão cheias de suspeita e de atitudes defensivas. 


\section{Demonstração de Autenticidade}

De acordo com George e Sims (2012) ninguém pode ser autêntico tentando ser outra pessoa. É possível aprender com as experiências dos outros, mas não há como ter sucesso tentando se parecer com eles. Os líderes autênticos além de inspirar as pessoas ao seu redor, lhes dão autonomia para assumir responsabilidades. George e Sims (2012, p. 29) afirma que “o líder autêntico une as pessoas ao redor de um propósito compartilhado e lhes dá autonomia para assumir responsabilidades, liderar de forma autêntica e assim gerar valor a todos os acionistas”. Líderes autênticos são pessoas sinceras que são fiéis consigo mesmo e com as suas crenças. Eles inspiram confiança e desenvolvem relações sinceras com os outros.

De acordo com Charan (2008) periodicamente o chefe e outras pessoas devem se reunir para trocar observações sobre ações, decisões e comportamentos do líder. Isso mostrará onde o líder está em seu estágio de desenvolvimento.

De acordo com Covey (2010) o líder influência através de seu exemplo e conduta. $\mathrm{O}$ caráter se revela no exemplo, mostrando quem realmente é a pessoa. $\mathrm{O}$ caráter está em constante comunicação, gerando confiança ou não.

De acordo com Neto (2006, p. 195) “a liderança pode ser entendida com um processo que visa liberar o potencial humano, o que significa mudar o foco do líder para o liderado" de acordo com a liderança servidora. Diante disso a "liderança nunca trará benefícios apenas para o líder; ao contrário, o primeiro e maior beneficiado será o liderado e somente por decorrência o líder”. Esta visão de liderança é altruísta, o cerne do processo está fora do alcance do líder, ou seja, "no outro (integridade), na sociedade (moralidade) e no ambiente (responsabilidade social)".

Segundo Robbins (2015) o feedback eficaz foca um comportamento específico e é impessoal. O feedback critica o comportamento das pessoas, mas não as pessoas 
em si. O feedback negativo deve ser dado se o funcionário tem controle sobre o comportamento, caso a pessoa não tenha controle não dever ter o comportamento criticado.

Para Kouzes e Posner (2013, p. 18) "quanto mais as pessoas confiam nos líderes e uma nas outras, mais se dispõem a correr riscos, a fazer mudanças e a perseverar o dinamismo das organizações e dos movimentos". As ações dos líderes contribuem mais para fatores como comprometimento, lealdade, motivação, orgulho e produtividade que qualquer outra variável isolada.

\section{Provisão de Liderança}

De acordo com Kouzes e Posner (2013) uma das práticas da liderança exemplar é inspirar uma visão comum. O futuro é incerto, não há garantias nem caminhos fáceis para qualquer destino, e as circunstâncias podem mudar a qualquer momento. Os líderes pioneiros seguem sua intuição e seus sonhos, olham para a frente e perscrutam o futuro. Os líderes devem induzir os outros a verem possibilidades vibrantes no futuro, animando as visões, comunicando esperança e sonhos para que os outros compreendam com clareza as visões e as compartilhem como se fossem próprias. As visões comuns atraem mais pessoas, sustentam níveis de motivação mais altos, além de melhor resistir aos desafios e dificuldades, em comparação com as visões individuais. O líder precisa ter a certeza de que o que vê também é visto pelos outros e vice-versa.

Para Senge (2014, p. 42) "quando existe uma visão genuína (em oposição à famosa 'declaração de missão'), as pessoas dão tudo de si e aprendem, não porque são obrigadas, mas porque querem". Compartilhar a visão, encontrando as imagens do futuro que gerem compromisso verdadeiro, em lugar de uma aceitação passiva dependa das habilidades do líder. 
De acordo com Covey (2005, p. 42) “a essência do ser humano é a capacidade de dirigir a própria vida. Os seres humanos agem; os animais e os 'robôs' humanos reagem. O ser humano pode fazer escolhas embasadas em seus valores". Nossa liberdade e capacidade de escolher completam o espaço entre o estímulo e a resposta. Mcchesney, Covey e Huling, (2013), ensinam que para se executar com êxito as organizações precisam de quatro disciplinas, que são:

1. Definir o que é crucialmente importante é focar em uma, duas ou no máximo três metas. Essas metas precisam ser tiradas do redemoinho de atividade e serem colocados em um lugar de destaque e serão chamadas de Metas Crucialmente Importantes. Então toda organização se une para a realização da meta.

2. Atuar nas medias de direção - define-se medidas diárias ou semanais cujas realizações levarão às metas crucialmente importantes.

3. Manter um placar envolvente - quando a equipe sabe se está ganhando ou perdendo ela dará o melhor de si e isso acontece quando a equipe tem acesso ao placar.

4. Criar uma cadência de responsabilidade - é realizada em uma reunião semanal onde se presta contas do que foi feito, revisa-se o placar e planeja-se as medidas de direção que levará a meta.

Segundo Bossidy e Charan (2005) é verdade que os líderes ainda devem definir o caminho adiante, mas é a execução que impulsiona a organização por esse caminho e permite que ela se beneficie das oportunidades. A execução passa por três processos, pessoas, estratégia e operações. Além de partilhar a visão o líder coloca as pessoas certas nos lugares corretos, conhece as estratégias e sabe que todas as variáveis são essenciais para transformar a visão em realidade. As operações para uma 
boa execução envolvem prestação de contas, metas claras, mensurar o desempenho e recompensas para as pessoas que apresentarem bom desempenho.

\section{Liderança Compartilhada}

George e Sims (2012) afirma é muito mais eficiente trabalhar com pessoas que tenham autonomia, paixão e propósito do que empregados que não passem de seguidores fiéis. Quando o líder inspira os empregados com uma visão comum, concedendo autonomia e liberdade para que eles liderem acontecer uma transformação na organização.

Para Senge (2014) alguns gerentes falam em convencer pessoas a comprar a visão. Existe um tremenda diferença entre vender e participar. Vender significa conseguir que alguém faça algo que talvez não tivesse domínio total de todos os fatos. Participar, significa literalmente fazer parte. “A participação implica na livre escolha. Participação é um processo de tornar parte de alguma coisa por opção” (p. 268). Assim o nível de participação é elevado para o comprometimento que transforma a participação, num “sentimento de total responsabilidade na transformação da visão em realidade" (p. 269). Se os liderados participam da definição da visão e se comprometem com ela, “a visão estará impulsionando suas ações” (p. 269).

Segundo Blanchard (2011) quando o líder consegue esclarecer e compartilhar sua visão, ele poderá focar em servir e se mostrar reativo às necessidades das pessoas, entendendo que o papel da liderança é remover obstáculos e ajudar as pessoas a concretizar a visão. Os maiores líderes mobilizam seus liderados unindo as pessoas em torno de uma visão comum. 


\section{Satisfação no Trabalho}

Segundo Lisboa (2006, p. 168) através das “teorias motivacionais modernas existentes, pode-se analisar, de forma qualitativa, o comportamento humano em relação à sua satisfação no trabalho".

Segundo Robbins (2010)

o trabalho de uma pessoa é mais do que organizar papéis, programar um computador, atender clientes ou dirigir um caminhão. O trabalho requer a convivência com colegas e superiores, a obediência às regras e políticas organizacionais, o alcance de padrões de desempenho, a aceitação de condições de trabalho geralmente abaixo do ideal e outras coisas do gênero. A avaliação que um funcionário faz de sua satisfação ou insatisfação com o trabalho é resultado de um complexo somatório de diferentes elementos. (p.73).

Teixeira (2012, p. 19) afirma que os resultados de estudos sobre satisfação no trabalho feitos no Brasil são raros e a situação das organizações brasileiras é pior que a de outros países. "Uma pesquisa da consultoria de recursos humanos Right Management realizada com 5.685 trabalhadores brasileiros obteve $48 \%$ de respostas negativas à pergunta: você é feliz no seu trabalho atual ou na sua última ocupação?”.

Para Teixeira (2012, p. 77) "a felicidade no trabalho tem ligação direta com o maior ou menor nível de consciência que as empresas e as pessoas tem de seu papel no mundo. Só dá para alguém ser feliz trabalhando e para uma empresa ficar feliz com o trabalho feito por esse alguém quando há um bom casamento de propósitos".

De acordo com Robbins (2010) para conseguir alta satisfação no trabalho e diminuição da rotatividade é necessário atrair e contratar pessoas cujos valores pessoais e personalidade sejam compatíveis com os valores e a cultura da empresa. Esse ajuste resultará em satisfação no trabalho, comprometimento com a organização e baixa rotatividade.

Robbins (2015) considera que há três fatores que desmotivam os funcionários no trabalho. Porque percebem uma fraca relação entre empenho e desempenho, entre 
desempenho e recompensas organizacionais e entre as recompensas que recebem e as que realmente desejam. Algumas avaliações de desempenho focam em fatores não necessariamente ligados ao desempenho, como lealdade ou iniciativa, então mais esforço não necessariamente resultará em uma avaliação positiva. Desempenho e recompensas são percebidos de maneira débil pelos funcionários porque a empresa recompensa por vários itens além de simplesmente o rendimento. $\mathrm{O}$ terceiro fator se relaciona com a recompensa recebida e a recompensa desejada. As recompensas precisam ser individualizadas de acordo com a necessidade dos funcionários na medida do possível, pois isso produzirá motivação e satisfação no trabalho.

De acordo com Chiavenato (2014b, p. 539) o clima organizacional é percebido, "experimentado pelos participantes da organização e influencia o comportamento". Um clima organizacional "menos burocrático com maior liberdade, delegação de responsabilidade, independência, permissão para arriscar, estímulos e recompensas constantes, clima caloroso, apoio a iniciativa individual e das equipes e respeito aos diversos pontos de vista são dimensões que tem influência poderosa na motivação das pessoas, no desempenho e na satisfação no trabalho" (p. 540).

\section{Resumo do Capítulo}

Este capítulo revisou de literatura que fundamenta teoricamente a pesquisa OLA. Os principais conceitos de Liderança foram apresentados os Estilos de Liderança, Teorias de Liderança, Liderança Servidora, as Seis Áreas-chave da Saúde Organizacional e Satisfação no Trabalho.

Na primeira parte foram considerados os diversos conceitos de liderança, tendo como ponto alto o conceito de Liderança Servidora, conceito de maior relevância nesta pesquisa. Na segunda parte, foram abordados os estilos de liderança: Autocrático, Democrático, Liberal, Visionária, Conselheira, Agregadora, modelar e 
Paternalista. Logo depois as principais teorias de liderança foram expostas: Teoria dos Traços de Personalidade, Teoria Situacional ou Contingencial, Teorias Transacionais, Teoria Transformacional.

A seguir foi considerado as Seis Áreas-chave de Saúde Organizacional: Valorização de Pessoas, Desenvolvimento de Pessoas, Construção de Comunidade, Demonstração de Autenticidade, Liderança Compartilhada e Provisão de Liderança. E por fim, foi abordado o tema da Satisfação no Trabalho. 


\section{CAPÍTULO 3}

\section{METODOLOGIA}

\section{Introdução}

O presente estudo analisou a percepção dos pastores da ACeAm sobre as práticas e estilos de liderança, a saúde organizacional e a satisfação no trabalho neste campo.

Este capítulo apresenta o tipo de pesquisa que foi aplicada e o instrumento de pesquisa que foi utilizado para medir o nível da saúde organizacional da ACeAm. Consta também a população onde aconteceu a investigação. Aborda-se como foi feita a coleta e o envio dos dados, o período em que a coleta foi realizada. Finalmente, demonstra como se realizou a análise dos dados recebidos.

\section{Tipo da Pesquisa}

O presente estudo é uma pesquisa do tipo quantitativo, de acordo com Diehl (2004) a pesquisa quantitativa usa a quantificação, na coleta e no tratamento das informações, através de técnicas estatísticas, buscando resultados que evitem possíveis variações da análise e interpretação dos dados, assegurando assim maior margem de segurança.

O instrumento de pesquisa OLA, próprio para uma pesquisa quantitativa foi utilizado com o objetivo de descobrir a percepção da área ministerial sobre o nível da saúde organizacional da ACeAm. 


\section{Instrumento da Pesquisa}

O presente estudo utilizou o instrumento de pesquisa OLA, desenvolvido por Laub (1999) com o fim de medir a saúde organizacional nas seguintes áreas chave: autenticidade, desenvolvimento de pessoas, valorização de pessoas, construção de comunidade, provisão de liderança e liderança compartilhada.

As seis áreas chave citadas acima são medidas a partir de um questionário contendo 66 (sessenta e seis) perguntas respondidas com a utilização da escala Likert, sendo 1 discordo fortemente e 5 concordo fortemente. As 66 perguntas são divididas em três seções: a primeira envolvendo todas as pessoas da organização, a segunda que se limita a liderança e a terceira que trata dos dados pessoais dos respondentes. Enviado diretamente aos indivíduos participantes da pesquisa via internet ao correio eletrônico, os dados do instrumento coletados eletronicamente pelo OLAGroup, detentor dos direitos do instrumento OLA, para análise e estatística.

Laub (1999) também usou o processo Delphi e um painel de especialistas para determinar a validade da pesquisa e descobriu que as construções eram válidas. Laub (1999) relatou que a confiabilidade do instrumento OLA, utilizando o coeficiente de Cronbach-Alfa, foi de 0,9802. De acordo com Laub (2005, citado em Miguel, 2009, p. 78) “o OLA foi desenvolvido através de um estudo focado na liderança servidora. Foi demonstrado ter alto nível de confiabilidade e validade".

\section{População}

A população pesquisada pelo presente estudo é constituída por 59 pessoas, que atuam em diferentes áreas do ministério, que atendendo ao requisito do instrumento de pesquisa OLA foram divididos da seguinte forma: três administradores da ACeAm que representam a Alta Liderança, 10 departamentais, sendo sete homens e três 
mulheres que representam o nível da Gerência, e 46 pastores distritais que representam a Força de Trabalho.

\section{Coleta de Dados}

A coleta foi realizada mediante contato direto do OLAGroup com os indivíduos participantes da pesquisa, através de seus correios eletrônicos informados pelo pesquisador, durante um período de 60 dias, entre 09 de julho e 09 de setembro de 2015 .

\section{Análise dos Dados}

Os dados sigilosamente coletados pelo instrumento de pesquisa OLA foram enviados ao OLAGroup eletronicamente para a apropriada análise estatística. Após realização da análise o OLAGroup enviou ao pesquisador a planilha organizada com todos os dados colhidos via WEB, possibilitando assim a construção das figuras e tabelas do presente estudo.

\section{Institutional Review Board}

O pesquisador recebeu autorização para a aplicação desta pesquisa, conforme Institutional Review Board (ver Apêndice A).

\section{Resumo do Capítulo}

O conteúdo deste capítulo apresentou qual é o tipo de pesquisa aplicada nesta dissertação, qual o instrumento de pesquisa que foi usado e qual a categoria do mesmo. Mostrou também a população pesquisada e a maneira como foi feita a coleta de dados. 


\section{CAPÍTULO 4}

\section{RESULTADOS}

\section{Introdução}

A aplicação desta pesquisa teve o objetivo de descobrir a percepção dos pastores, departamentais e administradores da ACeAm sobre as práticas e estilos de liderança, a saúde organizacional e a satisfação no trabalho neste Campo e sua relação com o conceito da Liderança Servidora. O objetivo é apresentar informações que definam o nível de Saúde Organizacional da instituição e motivem o desenvolvimento de ações que ajudem a melhorar as práticas e estilos de liderança servidora.

Este capítulo apresenta os resultados deste estudo, as características gerais dos respondentes e os resultados das seis áreas-chave de Saúde Organizacional que são:

1. Valorização de Pessoas

2. Desenvolvimento de Pessoas

3. Construção de Comunidade

4. Demonstração de Autenticidade

5. Provisão de Liderança

6. Liderança Compartilhada

Este capítulo também informa o resultado relacionado ao nível da satisfação no trabalho conforme as categorias de liderança, que são: Alta Liderança (administração), Gerência (departamentais) e a Força de Trabalho (pastores distritais). Os dados foram obtidos através da aplicação do instrumento de pesquisa OLA. A pesquisa tem um questionário de 66 perguntas que foram respondidas por 55 
participantes de uma população de 61 pessoas, sendo estes pastores, administradores, departamentais e distritais da ACeAm.

\section{Análise e Apresentação dos Dados}

O índice de respondentes da presente pesquisa é indicado pela Tabela 1.

Tabela 1

População e Respondentes

\begin{tabular}{lccc}
\hline Organização & População & Respondentes & \% Respondentes \\
\hline Associação Central Amazonas & 59 & 55 & $93,22 \%$ \\
\hline
\end{tabular}

O índice de respondentes pode ser considerado expressivo conforme apresentado na da Tabela 1, o que provavelmente demonstre interesse em participar da pesquisa visando expor sua percepção dos itens analisados neste trabalho. Responderam ao questionário 55 participantes (93\% do total de 59), entre os quais 34 são ministros ordenados e 21 ministros não ordenados.

A Tabela 2 apresenta a população dividida por categoria dos respondentes.

Tabela 2

População e Respondentes por Categoria

\begin{tabular}{lccc}
\hline Categoria & População & Respondentes & \% Respondentes \\
\hline Alta Liderança & 3 & 3 & $100 \%$ \\
Gerência & 10 & 10 & $100 \%$ \\
Força de Trabalho & 46 & 42 & $87,50 \%$ \\
Geral & 59 & 55 & $93,22 \%$ \\
\hline
\end{tabular}

As categorias com maior envolvimento foram a Alta Liderança e a Gerência, enquanto a categoria Força de Trabalho houve um envolvimento menor. 


\section{Análise do Nível de Saúde Organizacional}

A Tabela 3 apresenta a pontuação que define o nível da Saúde Organizacional de acordo com os resultados da pesquisa.

Tabela 3

Tabela de Pontuação para Definição do Índice de Saúde Organizacional

\begin{tabular}{lll}
\hline Pontuação & Nível & Índice de Saúde \\
Organizacional & Organizacional \\
\hline 4,50 a 5,00 & Org 6 & Saúde Excelente \\
4,00 a 4,49 & Org 5 & Saúde Ótima \\
3,50 a 3,99 & Org 4 & Saúde Moderada \\
3,00 a 3,49 & Org 3 & Saúde Limitada \\
2,00 a 2,99 & Org 2 & Saúde Pobre \\
1,00 a 1,99 & Org 1 & Saúde Tóxica \\
\hline
\end{tabular}

Há uma inversão de termos nos índices de saúde organizacional 5 e 6 na tradução para o português, para refletir a compreensão correta do índice em nossa língua.

A Saúde Tóxica revela a organização percebida como um lugar perigoso de trabalhar. Um lugar onde a força de trabalho sente-se desvalorizada.

A Saúde Pobre revela a organização percebida como autoritária. A força de trabalho não tem motivação pois não se sentem partes da organização.

A Saúde Limitada revela uma organização como paternalista no sentido negativo. A força de trabalho percebe níveis mínimos de credibilidade e confiabilidade, bem como altos índices de incerteza e medo.

A Saúde Moderada revela a organização como paternalista no sentido positivo. A força de trabalho percebe um nível moderado de credibilidade e confiabilidade, bem como incerteza e medo ocasionais. 
A Saúde Ótima revela a organização como vocacionada para o servir, caracterizada pela autenticidade, valorização e desenvolvimento das pessoas, construção de comunidade, estabelecimento e compartilhamento de liderança positiva.

A Saúde Excelente revela a organização como um espírito de serviço caracterizado pela autenticidade, valorização e desenvolvimento das pessoas, construção de comunidade, estabelecimento e compartilhamento de liderança positiva.

A análise dos resultados considerou os seis níveis de Saúde Organizacional, segundo especificado no instrumento OLA, como descritas a seguir na Figura 1.

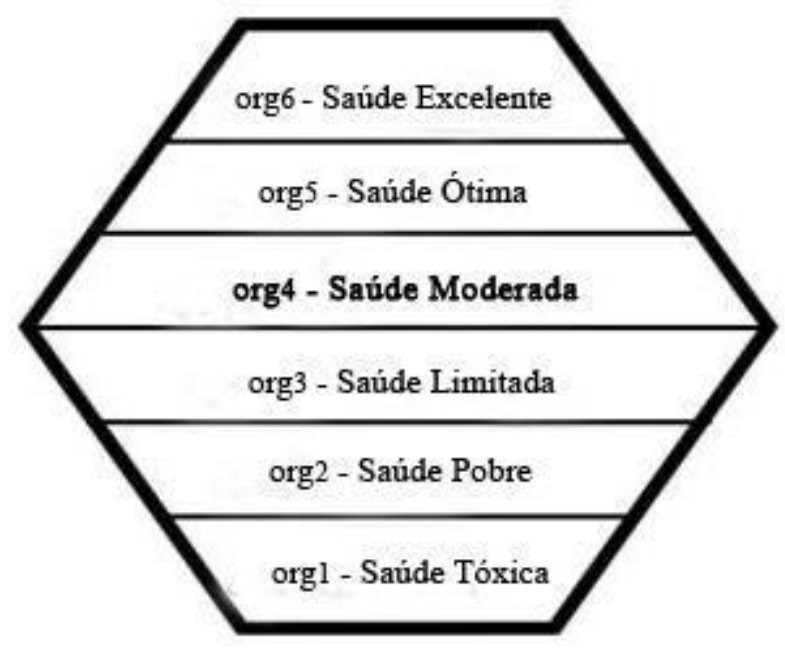

Figura 1. Nível de Saúde Organizacional da Associação Central Amazonas (ACeAm). Extraído do Relatório da Avaliação da Liderança Organizacional da $A C e A m$, por Jim Laub, p. 4.

A Figura 1 apresenta os seis níves de Saúde Organizacional e destaca o nível 4 que é a percepção dos respondentes.

A Tabela 4 apresenta o nível da Saúde Organizacional da ACeAm de acordo com os resultados da pesquisa. 
Tabela 4

Índice e Nível de Saúde Organizacional

\begin{tabular}{lccc}
\hline Organização & Índice & $\%$ & Nível de Saúde \\
\hline Associação Central Amazonas & 3,89 & 77,8 & Moderado \\
\hline
\end{tabular}

A população de respondentes demonstra uma percepção com o índice 3,89, que corresponde ao nível Moderado de Saúde Organizacional. Os resultados do relatório do OLA demonstram que o nível de Saúde Organizacional da Associação Central Amazonas se encontra numa fase intermediária, próxima ao nível seguinte superior. O instrumento OLA considera principalmente a pontuação da categoria Força de Trabalho para determinar a Saúde Organizacional (ver apêndice B).

A Tabela 5 apresenta os dados que correspondem ao índice e o nível da Saúde Organizacional da ACeAm por categoria.

Tabela 5

Índice e Nivel de Saúde Organizacional da ACeAm por Categoria

\begin{tabular}{lccc}
\hline Categoria & Índice & $\%$ & Nível de Saúde \\
\hline Alta Liderança & 4,29 & 85,9 & Ótimo \\
Gerência & 4,34 & 86,8 & Ótimo \\
Força de Trabalho & 3,89 & 77,8 & Moderado \\
\hline Geral & 3,92 & 78,4 & Moderado \\
\hline
\end{tabular}

Nota-se que a Gerência - departamentais e a Alta Liderança - administradores tem a percepção da saúde organizacional com índices mais alto da ACeAm cujo nível é Ótimo, e para a Força de Trabalho (pastores distritais) o índice é mais baixo caracterizando o nível de Saúde como Moderado. Os percentuais apresentados 
referem-se ao total alçando comparando que a Saúde Excelente está entre 90 e 100 por cento de pontos alcançados.

A Alta Liderança e a Gerência tem praticamente a mesma percepção da saúde organizacional da ACeAm com uma pequena variação nos índices e percentuais, mas apresentam o mesmo nível de Saúde que é classificado como Ótimo.

\section{Análise das Seis Áreas-Chave de Saúde Organizacional}

O instrumento de pesquisa OLA apresenta as seis áreas-chave de Saúde Organizacional, Valorização de Pessoas, Desenvolvimento de Pessoas, Construção de Comunidade, Demonstração de Autenticidade, Provisão de Liderança e Liderança Compartilhada.

A Tabela 6 apresenta os resultados da pesquisa do índice de Saúde Organizacional da ACeAm por área-chave. O resultado nesta tabela aparece em ordem decrescente para possibilitar a visualização das áreas mais fortes e mais fracas.

Tabela 6

Índice de Saúde Organizacional da ACeAm por ÁreaChave

\begin{tabular}{lcc}
\hline Área-Chave & Índice & $\%$ \\
\hline Provisão de Liderança & 4,17 & 83,33 \\
Construção de Comunidade & 3,89 & 77,76 \\
Liderança Compartilhada & 3,87 & 77,33 \\
Desenvolvimento de Pessoas & 3,85 & 76,98 \\
Valorização de Pessoas & 3,80 & 76,05 \\
Demonstração de Autenticidade & 3,79 & 75,87 \\
\hline Média Geral & 3,89 & 77,80 \\
\hline
\end{tabular}


Os resultados da Tabela 5 revelam que a pontuação mais alta ficou com a área de Provisão de Liderança. Já a pontuação mais baixa foi da área de Demonstração de Autenticidade.

A Figura 2 apresenta o nível de saúde organizacional das áreas-chave comparado com a pontuação média das outras organizações que utilizaram o instrumento OLA. A saúde organizacional da ACeAm foi determinada pelo resultado da Força de Trabalho (pastores distritais).

\begin{tabular}{|c|c|c|c|c|c|c|}
\hline & $\begin{array}{c}\text { Saúde Tóxica } \\
\text { org }^{\prime}\end{array}$ & | $\begin{array}{c}\text { Saúde Pobre } \\
\text { org }^{2}\end{array}$ & $\begin{array}{c}\text { Saúde Limitada } \\
\text { org }^{3}\end{array}$ & $\left|\begin{array}{c}\text { Saúde Moderada } \\
\text { org }^{4}\end{array}\right|$ & $\begin{array}{l}\text { Saúde Otima } \\
\text { org }\end{array}$ & $\begin{array}{l}\text { Saude Excelente } \\
\text { org }{ }^{6}\end{array}$ \\
\hline $\begin{array}{l}\text { Valoriza as } \\
\text { Pessoas }\end{array}$ & & & & & & \\
\hline
\end{tabular}

\begin{tabular}{|l|l|l|l|}
\hline $\begin{array}{l}\text { Capacita as } \\
\text { Pessoas }\end{array}$ & & & \\
\cline { 2 - 4 } & & & \\
\hline
\end{tabular}

\begin{tabular}{|l|l|l|l|}
\hline $\begin{array}{l}\text { Constrói uma } \\
\text { Comunidade }\end{array}$ & & & \\
\cline { 2 - 4 } & & & \\
\hline
\end{tabular}

\section{Revela}

Autenticidade



Provê

Liderança

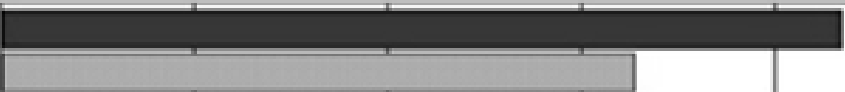

Compartilha a

Lideranca

= Pontuaçẫo médlia da Força de Trabalho

- Pontuação média de todas as organizaçōes que fizeram o OLA

Figura 2. Nível de Saúde Organizacional das áreas-chave da (ACeAm) comparado com a pontuação média de todas as organizações que fizeram o OLA. Extraído do Relatório da Avaliação da Liderança Organizacional da ACeAm, por Jim Laub, p. 7.

A Figura 2 permite analisar que a ACeAm possui um índice acima das demais organizações que utilizaram o OLA em todas as seis áreas-chave da Saúde Organizacional. A área de Provisão de Liderança é a área com a maior pontuação 
atingindo o nível de Saúde Ótimo, as demais áreas ficaram o nível de Saúde Moderada

A Tabela 7 apresenta o índice de Saúde Organizacional da ACeAm por categoria e por área-chave.

\section{Tabela 7}

Índice de Saúde Organizacional da ACeAm por Área-Chave e por Categoria

\begin{tabular}{lccc}
\hline Área-Chave & Alta Liderança & Gerência & $\begin{array}{c}\text { Força de } \\
\text { Trabalho }\end{array}$ \\
\hline Valorização de Pessoas & 4,30 & 4,09 & 3,80 \\
Desenvolvimento de Pessoas & 4,33 & 4,34 & 3,85 \\
Construção de Comunidade & 4,43 & 4,43 & 3,89 \\
Demonstração de Autenticidade & 4,14 & 4,27 & 3,79 \\
Provisão de Liderança & 4,22 & 4,71 & 4,17 \\
Liderança Compartilhada & 4,37 & 4,26 & 3,87 \\
& & & \\
\hline Média Geral & 4,29 & 4,34 & 3,89 \\
\hline
\end{tabular}

Os índices mais elevados apresentados na Tabela 7 estão nas áreas-chave de Provisão de Liderança, na categoria Gerência $(4,71)$, Construção de Comunidade, na categoria Alta Liderança $(4,43)$ e Provisão de Liderança na categoria Força de Trabalho $(4,17)$.

Percebe-se que a categoria Força de Trabalho apresenta um índice significativamente menor na área-chave Construção de Comunidade 3,89, a Gerência e Alta Liderança com 4,43.

Os menores índices estão na área de Demonstração de Autenticidade 3,79 pontuadas pela Força de Trabalho e 4,14 pontuados pela Alta Liderança, e na categoria Gerência área de Valorização de Pessoas pontuou 4,09. 
Nas área de Provisão de Liderança, as três categorias apresentam índices próximos. Na área-chave da Provisão de Liderança, as três categorias são unânimes ao considerar a saúde organizacional da ACeAm como positiva. As áreas-chave de Construção de Comunidade e Desenvolvimento de Pessoas a Alta Liderança e a Gerência tem a mesma percepção demonstrando o nível Ótimo.

A Figura 3 apresenta as seis áreas-chave da Saúde Organizacional por categoria de liderança.



Figura 3. Nível de Saúde Organizacional das áreas-chave da (ACeAm) por categoria. Extraído do Relatório da Avaliação da Liderança Organizacional da ACeAm, por Jim Laub, p. 9.

Segundo a percepção da Alta Liderança e da Gerência indicam para quase todas as áreas chave uma saúde organizacional Ótima. A única exceção está na área 
chave Provisão de Liderança que para a Gerência indica um índice de saúde Excelente.

Diferentemente da Alta Liderança e da Gerência, a Força de Trabalho percebe quase todas as áreas chave no nível de saúde organizacional Moderado, exceção feita à área Provisão de Liderança que indica um nível de saúde Ótimo.

A Tabela 8 revela os maiores índices das Áreas-Chave da Saúde Organizacional da ACeAm.

Tabela 8

Maiores Índices das Áreas-Chave de Saúde Organizacional da ACeAm

\begin{tabular}{lcc}
\hline Áreas-Chave & Índice & $\%$ \\
\hline Provisão de Liderança & 4,17 & 83,33 \\
Construção de Comunidade & 3,89 & 77,76 \\
\hline
\end{tabular}

As áreas-chave Provisão de Liderança e Construção de Comunidade alcançaram os maiores índices entre os respondentes.

A Tabela 9 revela os menores índices das Áreas-Chave da Saúde Organizacional da ACeAm.

Tabela 9

Menores Índices das Áreas-Chave de Saúde Organizacional da $A C e A m$

\begin{tabular}{lcc}
\hline Áreas-Chave & Índice & $\%$ \\
\hline Valorização de Pessoas & 3,80 & 76,05 \\
Demonstração de Autenticidade & 3,79 & 75,87 \\
\hline
\end{tabular}


A Tabela 9 demonstra que os menores índices da Saúde Organizacional da

ACeAm são as áreas-chave Valorização de Pessoas e Demonstração de

Autenticidade. Assim os respondentes revelam ser estas as áreas mais carentes da

ACeAm.

A Tabela 10 apresenta os maiores índices das Áreas-chave de Saúde

Organizacional da ACeAm por categoria.

Tabela 10

Maiores Índices das Áreas-Chave de Saúde Organizacional da ACeAm por Categoria

\begin{tabular}{llcc}
\hline Categoria & \multicolumn{1}{c}{ Áreas-Chave } & Índice & $\%$ \\
\hline Alta Liderança & Construção de Comunidade & 4,43 & 88,7 \\
& Liderança Compartilhada & 4,37 & 87,3 \\
Gerência & Provisão de Liderança & 4,71 & 94,2 \\
& Construção de Comunidade & 4,43 & 88,7 \\
\multirow{2}{*}{ Força de Trabalho } & Provisão de Liderança & 4,17 & 83,33 \\
& Construção de Comunidade & 3,89 & 77,76
\end{tabular}

Os resultados demonstram que na percepção das três categorias a área-chave Construção de Comunidade aparece como um dos dois maiores índice da Saúde Organizacional. Para a Alta Liderança a Construção de Comunidade recebeu a maior pontuação, já para a Gerência e para a Força de Trabalho a área Provisão de Liderança recebeu a maior pontuação.

A Tabela 11 demonstra os menores índices das Áreas-Chave da Saúde Organizacional da ACeAm por categoria.

A percepção da Alta Liderança e da Força de trabalho tende na mesma direção quanto à Demonstração de Autenticidade. Ambos indicam a menor pontuação para 
esta área-chave da Saúde Organizacional. Por outro lado, a percepção da Gerência e da Força de Trabalho

Tabela 11

Menores Índices das Áreas-Chave de Saúde Organizacional da ACeAm por Categoria

\begin{tabular}{llcc}
\hline Categoria & \multicolumn{1}{c}{ Áreas-Chave } & Índice & $\%$ \\
\hline Alta Liderança & Provisão de Liderança & 4,22 & 84,40 \\
& Demonstração de Autenticidade & 4,14 & 82,80 \\
Gerência & Liderança Compartilhada & 4,26 & 85,20 \\
& Valorização de Pessoas & 4,09 & 81,80 \\
\multirow{2}{*}{ Força de Trabalho } & 3,80 & 76,05 \\
& Valorização de Pessoas & 3,79 & 75,87 \\
& Demonstração de Autenticidade & & \\
& & &
\end{tabular}

indicam que a Valorização de Pessoas é a área de menor pontuação.

A Tabela 12 demonstra um comparativo da percepção da média da Organização e da Liderança dos participantes das três categorias.

Tabela 12

Comparativo da Percepção dos Participantes da Média da Organização e da Liderança

\begin{tabular}{lcc}
\hline Categoria & Organização & Liderança \\
\hline Alta Liderança & 4,29 & 4,30 \\
Gerência & 4,19 & 4,43 \\
Força de Trabalho & 3,79 & 3,94 \\
\hline Média Geral & 3,89 & 4,05
\end{tabular}

O termo Liderança da Tabela 12 refere-se a percepção da saúde da Organização e da Liderança da ACeAm, já o termo Organização aplica-se a percepção da instituição como um todo. A pontuação da percepção da Liderança é maior do que a pontuação da percepção da Organização. 
A Figura 4 ajudará a visualizar os índices demonstrados na Tabela 12.

A Figura 4 revela o comparativo da percepção das três categorias com respeito a Organização e a Liderança.



Figura 4. Comparativo da percepção dos participantes com respeito a Organização e a Liderança por categoria. Extraído do Relatório da Avaliação da Liderança Organizacional da ACeAm, por Jim Laub, p. 10.

A categoria Força de Trabalho percebe a Organização e a Liderança com o nível de Saúde Organizacional Moderado na ACeAm. A Alta Liderança e Gerência percebem a Organização e a Liderança com o nível de Saúde Organizacional Ótimo.

\section{Análise do Estilo de Liderança e do Nível de Saúde Organizacional}

O Estilo de Liderança representa o que o líder faz, seu comportamento ao liderar. O nível de Saúde Organizacional é resultante dos estilos de liderança, Autocrática, Paternalista e Servidora.

A Tabela 13 apresenta os Estilos de Liderança e os Níveis de Saúde Organizacional utilizados pela OLA para classificar as organizações. 
Tabela 13

Estilos de Liderança e os Níveis de Saúde Organizacional

\begin{tabular}{lll}
\hline \multicolumn{2}{c}{ Estilo de Liderança } & Nível de Saúde \\
\hline Liderança Servidora & Servidora & Excelente \\
& Orientada à Servidora & Ótimo \\
\hline Liderança Paternalista & Paternalismo Positivo & Moderado \\
& Paternalismo Negativo & Limitado \\
\hline Liderança Autocrática & Autoritário Autocrático & Pobre \\
& Autoritário Perigoso & Tóxica \\
\hline
\end{tabular}

A Tabela 14 apresenta e Estilo de Liderança da ACeAm.

Tabela 14

Índice e Estilo da Liderança da ACeAm

\begin{tabular}{lccc}
\hline Organização & Índice & $\%$ & Estilo de Liderança \\
\hline Associação Central Amazonas & 3,89 & 78 & Paternalista Positivo \\
\hline
\end{tabular}

A percepção dos participantes da pesquisa OLA indica que o estilo de Liderança da ACeAm é Paternalista Positivo. A liderança assume o papel de pai que cuida dos liderados como crianças.

A Tabela 15 apresenta o índice e o estilo de liderança por categoria.

Tabela 15

Índices e Estilo de Liderança por Categoria

\begin{tabular}{lccc}
\hline Categoria & Índice & $\%$ & Estilo de Liderança \\
\hline Alta Liderança & 4,29 & 85,8 & Orientado à Servidora \\
Gerência & 4,34 & 86,8 & Orientado à Servidora \\
Força de Trabalho & 3,89 & 77,8 & Paternalista Positivo \\
\hline
\end{tabular}


A pontuação do índice de Liderança por categoria demostra que a percepção da Alta Liderança e Gerência como Estilo Orientado à Servidora. Já a Força de Trabalho percebe o Estilo de Liderança como Paternalista Positivo.

\section{Análise do Índice de Satisfação no Trabalho}

O instrumento de pesquisa OLA aplicado na ACeAm analisou o nível de Satisfação no Trabalho dos participantes. O resultado demonstra a percepção dos respondentes por categoria. Para se chegar a esta conclusão foram considerados seis itens de satisfação obtidos através das seguintes perguntas:

1. Eu me sinto bem sobre a minha contribuição para a organização?

2. O meu trabalho é importante para o sucesso da organização?

3. Eu estou trabalhando em um alto nível de produtividade?

4. Gosto de trabalhar nessa organização?

5. Eu sou capaz de ser criativo no meu trabalho?

6. Eu posso usar meus melhores dons e habilidades no meu trabalho?

A Figura 5 apresenta o resultado da Satisfação no Trabalho da ACeAm por categoria.

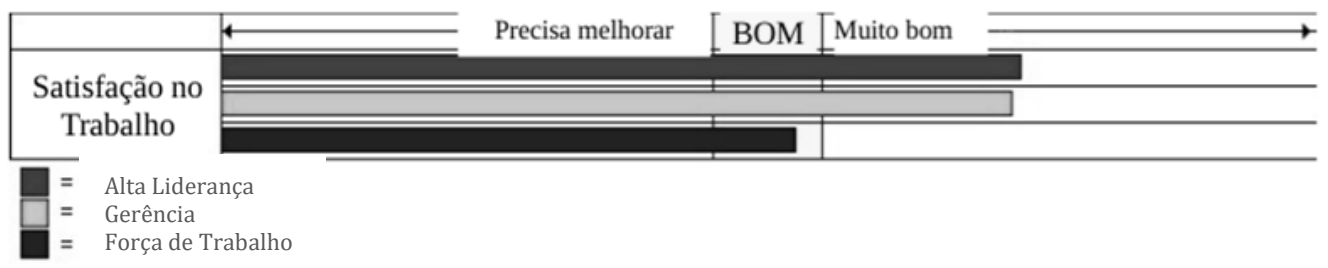

Figura 5. Resultado da Satisfação no Trabalho da ACeAm por categoria. Extraído do Relatório da Avaliação da Liderança Organizacional da ACeAm, por Jim Laub, p. 11.

A Figura 5 apresenta o resultado da Satisfação no Trabalho na ACeAm por categoria. Para a Alta Liderança e Gerência o nível de Satisfação no Trabalho é 
classificado como Muito Bom. Já a Força de Trabalho classificou a Satisfação como Bom.

A Tabela 16 apresenta o índice e o percentual de Satisfação no Trabalho na ACeAm.

Conforme critério do OLA, a Satisfação no Trabalho da organização pesquisada é baseada nos dados gerados pela categoria da Força de Trabalho.

Tabela 16

Índice de Satisfação no Trabalho

\begin{tabular}{lcc}
\hline Organização & Índice & $\%$ \\
\hline Associação Central Amazonas & 4,22 & 84,37 \\
\hline
\end{tabular}

O índice de Satisfação de Trabalho da organização conforme a percepção da Força de Trabalho é Bom.

A Tabela 17 demonstra o índice e o Percentual de Satisfação no Trabalho da ACeAm por Categoria.

Tabela 17

Índice de Satisfação no Trabalho por Categoria

\begin{tabular}{lcc}
\hline Categoria & Índice & $\%$ \\
\hline Alta Liderança & 4,61 & 92,22 \\
Gerência & 4,60 & 92 \\
Força de Trabalho & 4,22 & 84,37 \\
\hline Geral & 4,48 & 89,53 \\
\hline
\end{tabular}


O índice de Satisfação no Trabalho na ACeAm apresenta uma variação. A Alta Liderança e a Gerência ficaram com o maior índice com uma variação mínima. A Força de Trabalho ficou com o menor índice, que indica Satisfação Boa.

\section{Resumo do Capítulo}

O conteúdo deste capítulo apresentou qual é o tipo de pesquisa aplicada nesta dissertação, qual o instrumento de pesquisa que foi usado e qual a categoria do mesmo. Mostrou também a população pesquisada e a maneira como foi feita a coleta de dados. Através de figuras e tabelas foram apresentados dados e resultados da pesquisa cujo instrumento OLA revelou considerando as práticas, estilos de liderança, o nível de Saúde Organizacional e o índice de Satisfação no Trabalho da ACeAm. 


\section{CAPÍTULO 5}

\section{CONCLUSÕES E RECOMENDAÇÕES}

\section{Introdução}

Este estudo teve como objetivo descobrir a percepção dos pastores da ACeAm relacionada com a liderança servidora, verificando o nível da Saúde Organizacional, as práticas e os estilos de liderança, e também a satisfação no trabalho nesta instituição. Neste capítulo pode-se analisar a síntese do trabalho realizado demonstrando as principais descobertas e conclusões da pesquisa, além disso apresentar as recomendações para a realização de novos estudos e desenvolvimento de novas práticas que ajudem a melhorar o nível de Saúde Organizacional se aproximando das práticas mais próximas da Liderança Servidora, aumentando o nível de saúde organizacional e também melhorando o nível de satisfação no trabalho.

\section{Resumo do Estudo}

O principal objetivo do presente estudo foi identificar dados sobre a Saúde Organizacional, as práticas, os estilos de liderança e a Satisfação no Trabalho da ACeAm de maneira a descobrir os pontos fortes e fracos para que ações práticas e relevantes fossem sugeridas para implementar um melhor nível de saúde até atingir a saúde excelente.

A pesquisa aplicada foi de caráter quantitativo e a população foi constituída por pastores da ACeAm organizados em três categorias. A Alta Liderança - 
administradores), a Gerência - departamentais) e a Força de trabalho - pastores distritais.

O instrumento de pesquisa utilizado neste estudo foi o OLA, desenvolvido por Jim Laub, presidente do Olagroup, que detém os direitos deste instrumento. Obtendo a aprovação da Comissão de Ética concedida pela Andrews University (ver Apêndice A) e os devidos acertos com o Olagroup, a pesquisa foi aplicada. A pesquisa contém um questionário com 66 questões que foi aplicada no mês setembro de 2015. As questões analisam as seis áreas-chave de Saúde Organizacional: Valorização de Pessoas, Desenvolvimento de Pessoas, Construção de Comunidade, Provisão de Liderança, Demonstração de Autenticidade e Liderança Compartilhada. A pesquisa também considerou o nível de Satisfação no Trabalho da instituição. O Olagroup recebeu os endereços eletrônicos dos participantes, os quais responderam a pesquisa individualmente de forma eletrônica (on-line) através do site fornecido pela entidade. Em seguida, a entidade responsável pela tabulação apresentou um relatório com as devidas considerações e análises das respostas obtidas através do OLA.

\section{Descobertas}

A pesquisa aplicada utilizando o instrumento OLA revela o nível da saúde organizacional da ACeAm a partir da observação dos pastores que se dividem em três categorias. Dos 59 pastores que foram contatados, 55 responderam a pesquisa, sendo três da Alta Liderança, 10 da Gerência e 42 da Força de Trabalho. O instrumento OLA considera seis níveis de Saúde Organizacional: Tóxica, Pobre, Limitada, Moderada, Excelente e Máxima. A pesquisa demonstrou que a Saúde Organizacional da ACeAm é Moderada. O estilo de liderança percebido é o Paternalista Positivo liderada por pais. A pesquisa caracterizou a ACeAm como uma organização com um nível moderado de confiança e credibilidade, havendo um sentimento de medo e 
incerteza ocasionais. De acordo com a pesquisa a criatividade é encorajada, desde que não se mova a organização muito além do seu estado atual. Pode-se correr riscos, mas as vezes o fracasso é temido. As metas da organização são, na sua maior parte claras, embora a direção geral seja, por vezes, confusa.

A pesquisa revelou que a Saúde Organizacional da ACeAm está caracterizada de Moderada a Boa e está operando com esta característica na maioria de seus níveis de operação quanto aos seus distritais, liderança e cultura organizacional.

A Força de Trabalho - pastores distritais, em sua maioria se sentem valorizados, quanto a motivação, moral, atitude e compromisso, compreensão e também quanto o relacionamento versus a tarefa, enquanto outros não tem certeza. As pessoas recebem treinamento nesta organização para equipa-las a atingirem as metas da organização. Os distritais geralmente são ouvidos, quando eles falam de acordo com os valores e prioridade de seus líderes. As ideias dos distritais são procuradas e algumas vezes usadas, mas as decisões importantes permanecem nos níveis mais altos da organização. Os relacionamentos são valorizados à medida em que beneficiam as metas da companhia, mas as tarefas da organização vem em primeiro lugar. Existe uma tensão entre a expectativa de conformidade e o encorajamento da diversidade.

Quanto a Liderança, o poder, tomada de decisões, metas e direção exercem o estilo de liderança paternalista positivo e a maior parte vem dos níveis máximos da organização. Os líderes frequentemente assumem o papel de pais provedores, enquanto os distritais assumem o papel de filhos. O poder é delegado para tarefas específicas e para posições específicas dentro da organização.

Com relação ao Trabalho em Equipe, o senso de comunidade, colaboração e aprendizado, a pesquisa demonstrou que há certo nível de trabalho cooperativo, e 
alguma colaboração verdadeira. As equipes são usadas, mas podem competir uma com a outra no caso de escassez de recursos.

Sobre a Cultura Organizacional da ACeAm no que diz respeito a autenticidade, integridade, responsabilidade, criatividade, confiança, serviço e comunicação a pesquisa mostra as vezes os distritais estão inseguros de sua posição e de quão abertos podem ser um com o outro, especialmente com aqueles que estão na liderança acima deles. Neste ambiente pode-se assumir riscos, mas às vezes o fracasso é temido. Existe encorajamento para serem criativos, desde que não mova a organização para muito além do seu estado atual. Há um nível moderado de confiança nos outros, mas sabem que essa confiança pode ser facilmente perdida. As pessoas são motivadas para servirem a organização porque é seu trabalho fazer isso, visto estarem comprometidas a fazerem um bom trabalho. Esse é um ambiente caracterizado pela transparência entre grupos específicos de pessoas.

Quanto a Perspectiva quanto ao tipo de distritais atraídos e ação necessária a organização positivamente paternalista, atrairá trabalhadores motivados, mas os mais criativos vão procurar desafios profissionais em outro lugar. A mudança na ACeAm é constante, mas frequentemente forçada por circunstâncias externas. A melhoria é desejada, mas difícil de se manter com o tempo. A perspectiva para esta organização é positiva. Decisões precisam ser tomadas para se alcançar uma vida organizacional mais saudável. Essa organização está numa boa posição para alcançar a saúde máxima no futuro.

Com respeito ao nível de Satisfação no Trabalho da Força de Trabalho é Bom, pois acreditam que estão dando sua contribuição pessoal pela organização, e que seu trabalho é importante para o sucesso da mesma. Eles acreditam que são capazes de usar seus melhores dons e habilidades enquanto são criativos no seu trabalho. Eles 
apreciam o trabalho que fazem e creem que estão pessoalmente trabalhando num alto nível de produtividade.

\section{Perguntas e Respostas da Pesquisa}

Questão 1

Qual o nível de Saúde Organizacional da Associação Central Amazonas na percepção da área ministerial?

Os dados fornecidos pela pesquisa demonstram que o nível de Saúde Organizacional da ACeAm é Moderado.

As três categorias, Alta Liderança, Gerência e Força de Trabalho foram analisadas e os dados revelaram percepções diferentes com respeito ao nível de Saúde Organizacional e do estilo de liderança da instituição.

A Alta Liderança e a Gerência veem o nível de Saúde Organizacional como Excelente e o estilo de liderança da organização como Vocacionada para Servir. Este resultado demonstra a percepção da Alta Liderança e da Gerência que veem que há autenticidade, valorização, desenvolvimento das pessoas, construção de comunidade, estabelecimento e compartilhamento de liderança positiva. Há confiança entre as pessoas. Há interesse em servir aos interesses um dos outros, antes que o seu próprio interesse, além de estarem abertas a aprenderem umas com as outras. Estas categorias ainda veem-se um ao outro como colegas de trabalho num espirito de colaboração.

A percepção da Força de Trabalho que é a base pare verificar o nível de Saúde Organizacional revelou através dos dados que é Moderado e o estilo de liderança é Paternalista Positivo. Os pastores distritais (Força de Trabalho) em sua maioria se sentem valorizados, enquanto outros não tem certeza disso. Os distritais geralmente são ouvidos, quando eles falam de acordo com os valores e prioridade de seus líderes. As ideias dos distritais são procuradas e algumas vezes usadas, mas as decisões 
importantes permanecem nos níveis mais altos da organização. Os relacionamentos são valorizados à medida em que beneficiam as metas da companhia, mas as tarefas da organização vem em primeiro lugar. Existe uma tensão entre a expectativa de conformidade e o encorajamento da diversidade.

Essa percepção diferente do nível de Saúde Organizacional e do estilo de liderança sugere um nível limitado de consciência compartilhada e comunicação aberta entre a Alta Liderança, a Gerência e Força de Trabalho.

Na ACeAm a percepção da Alta Liderança e da Gerência sobre o nível de Saúde Organizacional é Ótimo e é necessário cultivar práticas de liderança servidora para atingir o nível de Saúde Excelente. Diante da percepção da Força de Trabalho há necessidade de melhorar nas seis áreas-chave, porém com uma atenção especial a Valorização de Pessoas e Demonstração de Autenticidade.

\section{Questão 2}

Quais as práticas e estilos de liderança que receberam as maiores e as menores pontuações?

Conforme a pesquisa com o instrumento OLA o resultado das seis áreas-chave da Saúde Organizacional da ACeAm foram pontuadas da maior para a menor, na seguinte sequência:

1. Provisão de Liderança

2. Construção de Comunidade

3. Liderança Compartilhada

4. Desenvolvimento de Pessoas

5. Valorização de Pessoas

6. Demonstração de Autenticidade 
Assim, as duas áreas-chave da Saúde Organizacional que receberam as maiores pontuações na pesquisa em relação às demais são Provisão de Liderança e Construção de Comunidade.

O índice mais elevado ficou com a área-chave Provisão de Liderança que demonstra que a liderança consegue estabelecer uma visão comum de futuro, apesar do futuro ser incerto a liderança consegue compartilhar sonhos de maneira que a força de Trabalho compreenda com clareza as visões de futuro e compartilhem como se fossem deles próprios. Para Laub (1999) a provisão de liderança acontece quando o líder tem bem claro uma visão de futuro, tem iniciativa e esclarece as metas e objetivos. Esta ação é essencial para os liderados sentirem-se seguros. Para Senge (2014, p. 42) “quando existe uma visão genuína (em oposição à famosa 'declaração de missão'), as pessoas dão tudo de si e aprendem, não porque são obrigadas, mas porque querem".

A liderança da ACeAm consegue envolver os pastores na definição da visão, $\operatorname{dos}$ objetivos e metas da organização através de reuniões de planejamento participativo onde temos a presença de líderes locais e pastores distritais. Provavelmente os itens que influenciaram este resultado foram clareza quanto as metas principais da organização, comunicam com clareza a visão de futuro, decisões adequadas pela liderança e provisão de suporte para ajudar os distritais a alcançar as metas.

$\mathrm{Na}$ área-chave construção de comunidade, Blanchard (2011) defende que para liderar em alto nível não se foca apenas a realização dos objetivos, mas é preciso pensar no "bem maior, aquilo que é melhor para todos os envolvidos, porque a liderança é um chamado superior” (p. xvi). "Liderar em alto nível é um processo de alcançar resultados que valham a pena ao mesmo tempo em que tratamos os liderados 
com respeito e consideração. Hoje precisa-se de líderes que sirvam os liderados e os lidere depois" (p. xvii).

Senge (2014) afirma que a palavra líder passou a se referir a uma posição de autoridade, mas o verdadeiro líder é aquele em quem seus liderados confiam. Esta confiança é resultado de uma demonstração sincera por parte do líder pelo bem-estar do liderado. A ideia de líderes que servem àqueles que lideram pode parecer idealista, mas é muito pragmática. Para Senge (2014, p. 509) “ser líder é ser guia que significa servir a um objetivo maior".

A ACeAm alcançou um bom índice nesta área provavelmente porque esforçam-se relacionamentos de trabalho saudáveis, valorizam diferenças de cultura, raça e etnia, os líderes facilitam a construção de equipe e comunidade além de encorajar o trabalho juntos ao invés de competirem uns com os outros.

As áreas-chave menos pontuadas são as seguintes: Valorização de Pessoas e Demonstração de Autenticidade.

$\mathrm{Na}$ área-chave Valorização de Pessoas a Alta Liderança e a Gerência tem percepções muito similares demonstrando o nível Excelente, porém a Força de Trabalho percebe de forma diferente e os dados revelam a classificação como nível Moderado. O índice revelado pela força de trabalho indica necessidade de promover a confiança entre as pessoas nesta organização, maior consciência das necessidades uns dos outros e dar maior atenção as necessidades da Força de Trabalho. Para Chiavenato (2014a) na nova visão do RH as pessoas são o principal recurso da organização. Então é importante tomar decisões sempre pensando no bem do funcionário.

Segundo Lisboa (2006, p. 169) “a hierarquia das necessidades desenvolvida por Abraham Maslow, apresenta a identificação de um conjunto de impulsos 
denominado necessidades. Agrupou as necessidades em níveis hierárquicos, cujo grau de importância influencia o comportamento humano". As necessidades são: necessidades fisiológicas, segurança, sociais e de auto-realização, Para valorizar as pessoas é necessário atender estas necessidades.

$\mathrm{Na}$ Demonstração de Autenticidade, a força de trabalho da ACeAm revelou uma percepção diferente da Alta Liderança e da Gerência nesta área-chave de Saúde Organizacional. George e Sims (2012, p. 29) afirma que "o líder autêntico une as pessoas ao redor de um propósito compartilhado e lhes dá autonomia para assumir responsabilidades, liderar de forma autêntica e assim gerar valor a todos os acionistas”. Líderes autênticos são pessoas sinceras que são fiéis consigo mesmo e com as suas crenças. Eles inspiram confiança e desenvolvem relações sinceras com os outros.

Segundo Robbins (2015) o feedback eficaz foca um comportamento específico e é impessoal. O feedback critica o comportamento das pessoas, mas não as pessoas em si. O feedback negativo deve ser dado se o funcionário tem controle sobre o comportamento, caso a pessoa não tenha controle não dever ter o comportamento criticado.

O resultado deste estudo sugere que os líderes na ACeAm devem atentar para está área-chave admitindo seus erros e limitações pessoais, receber críticas e aprender com os liderados.

\section{Questão 3}

Qual o nível de satisfação no trabalho entre os que compõem a força de trabalho deste estudo?

A Força de Trabalho pontuou o nível $(4,22)$ da pesquisa cuja percepção considera o índice de Satisfação no Trabalho como Bom. As categorias Alta 
Liderança $(4,61)$ e Gerência $(4,60)$ apresentam níveis de satisfação próximos, e são considerados Muito Bom.

De acordo com Robbins (2010) para conseguir alta satisfação no trabalho e diminuição da rotatividade é necessário atrair e contratar pessoas cujos valores pessoais e personalidade sejam compatíveis com os valores e a cultura da empresa. Esse ajuste resultará em satisfação no trabalho, comprometimento com a organização e baixa rotatividade.

De acordo com Chiavenato (2014b, p. 539) o clima organizacional é percebido, “experimentado pelos participantes da organização e influencia o comportamento". Um clima organizacional "menos burocrático com maior liberdade, delegação de responsabilidade, independência, permissão para arriscar, estímulos e recompensas constantes, clima caloroso, apoio a iniciativa individual e das equipes e respeito aos diversos pontos de vista são dimensões que tem influência poderosa na motivação das pessoas, no desempenho e na satisfação no trabalho" (p. 540).

\section{Conclusões}

Neste estudo a ACeAm ficou caracterizada com o nível de Saúde Organizacional Moderado. Os distritais veem a organização como paternalista, no sentido positivo. A organização é caraterizada por um nível moderado de confiabilidade e credibilidade e uma incerteza e medo ocasionais. A criatividade é encorajada, contanto que não se mova muito além do estado atual. Há incentivo para se correr riscos, mas existe o temor pelo fracasso. As metas são claras, mas às vezes a direção parece confusa.

As pessoas sentem a confiança dos outros, mas sabem que esta pode ser facilmente perdida. As pessoas são motivadas a servir a organização porque é seu 
trabalho fazer isso, visto estarem comprometidas a fazer um bom trabalho. Este é um ambiente caracterizado pela transparência entre grupos específicos.

Muitos distritais sentem que são valorizados, enquanto outros tem dúvida. Os pastores recebem treinamento para equipa-los para atingirem as metas da organização. Eles são ouvidos, mas geralmente isso acontece quando falam de acordo com os valores e prioridades de seus líderes. Suas ideias são procuradas e algumas vezes usadas, mas as decisões mais importantes permanecem nos níveis mais altos da organização. Os relacionamentos são valorizados a medida que beneficiam as metas da organização, mas as tarefas da organização frequentemente vem em primeiro lugar. Essa organização está numa boa posição para alcançar saúde Excelente no futuro.

O estilo de liderança na ACeAm é paternalista positivo percebido pela categoria Força de Trabalho - pastores distritais. A Alta Liderança - administradores e a Gerência - departamentais percebem a saúde com o estilo Orientada à Servidora . A relação entre líderes e liderados é muitas vezes como a relação entre pais e filhos. Há incentivo para se compartilhar ideias a fim de melhorar a organização. A pesquisa demostra que os pastores não sabem como ser abertos uns com os outros, em especial,

com aqueles que estão na liderança. É necessário melhorar o nível de consciência compartilhada e comunicação aberta.

O índice de Satisfação no Trabalho da ACeAm é Bom e denota uma Saúde Organizacional Moderada.

\section{Recomendações}

O resultado do estudo realizado na ACeAm, tendo o objetivo de saber qual a percepção dos pastores sobre da liderança servidora neste Campo, ajuda a sugerir as seguintes recomendações: 
1. Apresentar aos pastores distritais, departamentais e administradores qual o nível de Saúde Organizacional, índice de Satisfação no Trabalho e práticas e estilos de liderança experimentados na ACeAm na época em que o estudo foi realizado. Isto poderá ser feito nos concílios pastorais, nas comissões internas e nos Pequenos Grupos Pastorais, incluindo a discussão de ações que estimulem a prática de liderança servidora na ACeAm.

2. As áreas-chave Valorização de Pessoas e Demonstração de Autenticidade que receberam os menores índices de saúde organizacional, gera preocupação e sugere realizar uma reunião para estudar estes dois assuntos, permitindo aos pastores sugerir medidas para promover a mudança desta realidade, para criar uma cultura de liderança servidora na ACeAm.

3. Organizar uma série de ações ao longo de um período suficiente para proporcionar a conscientização do grupo sobre a relevância das necessárias mudanças e práticas que estimulem a contínua melhora da Saúde Organizacional e a Satisfação no Trabalho na ACeAm. A proposta visa ter como foco o estudo da teoria da Liderança Servidora, baseando-se no plano de ação organizacional de Laub (2015) que propõe os seguintes passos para uma organização saudável:

3.1. Avaliar o nível da saúde organizacional e da liderança pelo instrumento OLA, além da disposição para mudança para esclarecer a base para a mudança organizacional positiva e duradoura;

3.2. Acompanhamento de Grupo de Ação: dentro de um ambiente facilitador e seguro, o grupo todo identificará prioridades para a ação em cada uma das seis áreas-chave para trazer melhorias para a organização; 
3.3. Treinamento com Metas: preparar um treinamento de alto impacto para todos os níveis da organização, focando as áreas de suas maiores necessidades e de seus maiores potenciais;

3.4. Desenvolvimento da Organização: comprometer-se com estratégias de mudança organizacional que levam a uma cultura organizacional mais saudável.

\section{Sugestões Para Estudos Posteriores}

Este estudo abordou o tema da liderança servidora, segundo a percepção do ministério das três categorias de liderança na Associação Central Amazonas da Igreja Adventista do Sétimo Dia. Os resultados permitem fazer recomendações e sugestões para estudos posteriores:

Sugere-se realizar pesquisa acerca da prática de liderança servidora na ACeAm nos distritos pastorais para saber a percepção dos membros das igrejas organizadas, em comparação com os líderes locais e a administração da igreja.

Recomenda-se realizar a pesquisa com a área educacional, com o foco em descobrir a percepção dos professores com respeito a saúde organizacional, estilo e práticas de liderança e satisfação no trabalho.

Sugere-se realizar a pesquisa com a área de publicações, com o foco em descobrir a percepção dos colportores com respeito a saúde organizacional, estilo e práticas de liderança e satisfação no trabalho. 
APÊNDICE A

CARTA DO COMITÊ DE ÉTICA DA ANDREWS 


\section{Andrews DUniversity}

April 13, 2015

Sergio Alan Caxeta

Tel: $\quad+55$ (92) 981230405

Email: sergioalan@me.com

RE: APPLICATION FOR APPROVAL OF RESEARCH INVOLVING HUMAN SUBJECTS

IRB Protocol \#: 15-035 Application Type: Original Dept.: Leadership

Review Category: Expedited Action Taken: Approved Advisor: Eliseu Menegusso

Title: A Study on the Perception of Pastors of Central Amazon Conference of the Seventh-day

Adventist Chruch Regarding Organizational Health, Practices and Leadership Styles, and the Level of Satisfaction at Work.

This letter is to advise you that the Institutional Review Board (IRB) has reviewed and approved your IRB application of research involving human subjects entitled: "A study on the perception of pastors of central Amazon conference of the Seventh-day Adventist church regarding organizational health, practices and leadership styles, and the level of satisfaction at work" IRB protocol number 15-035 under Expedited category. This approval is valid until April 13, 2016. If your research is not completed by the end of this period you must apply for an extension at least four weeks prior to the expiration date. We ask that you inform IRB whenever you complete your research. Please reference the protocol number in future correspondence regarding this study.

Any future changes (see IRB Handbook pages 10-11) made to the study design and/or consent form require prior approval from the IRB before such changes can be implemented. Please use the attached report form to request for modifications, extension and completion of your study.

While there appears to be no more than minimum risk with your study, should an incidence occur that results in a research-related adverse reaction and/or physical injury, (see IRB Handbook page 11) this must be reported immediately in writing to the IRB. Any project-related physical injury must also be reported immediately to the University physician, Dr. Reichert, by calling (269) 473-2222. Please feel free to contact our office if you have questions.

Best wishes in your research.

Sincerely

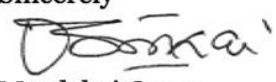

Mordekai Ongo

Research Integrity \& Compliance Officer

Institutional Review Board - 4150 Administration Dr Room 322 - Berrien Springs, MI 49104-0355

Tel: (269) 471-6361 Fax: (269) 471-6543 E-mail: irb@andrews.edu 
APÊNDICE B

RELATÓRIO DA AVALIAÇÃO DA LIDERANÇA ORGANIZACIONAL (OLA) 


\section{O RGANIZATIONAL L EADERSHIP A SSESSMENT}

Evaluation Report for:

Associação Central Amazonas da Igreja Adventista do Sétimo Dia (ACeAm) 
OLA

Table of Contents

I | OLA Results Overview

Ranking and Explaining the Six Key Areas

Page 3

Executive Summary

Page 4-5

II Health Level

Detailed Results of the Six Key Areas

Page 6

Your Expanded Organizational Health Description

Page 7

Descriptions of all Six Organizational Health Levels

Page 8

III Perception Match

Perception Match - The Six Key Areas

Page 9

Perception Match - Organization \& Leadership

Page 10

IV | Job Satisfaction

Page 11

v Readiness for Change

Page 12-13

vI Detailed Item Report \& Summary

Summary - collecting the six highest and lowest items

Page 14-18

Results by individual items

vII Creating Your Improvement Action Plan

A Path toward Shared Action

Moving toward Organizational improvement 


\section{The Organizational Leadership Assessment (OLA)}

measures six characteristics of organizational and leadership practice that are critical to optimal organizational health and determine an organization's Health Level. The OLA also measures the Perception Match of the workforce and leadership concerning the organization's health. These six areas characterize organizations that provide authentic and shared leadership, empowered workers and a community of people who work effectively together to fulfill the organization's mission. The six characteristics are listed and expanded below.

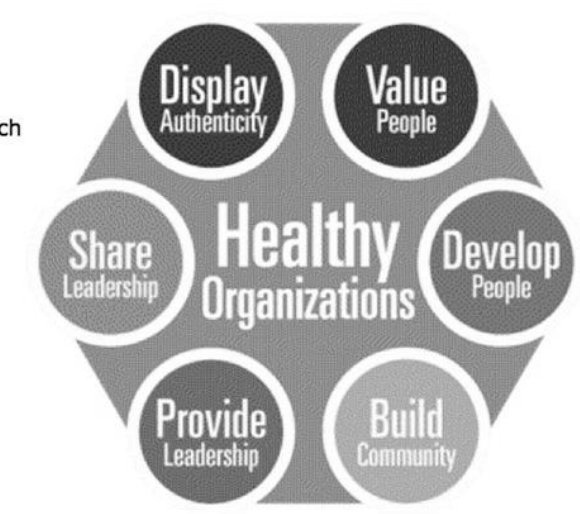

In Your Organization, the Six Characteristics Ranked Highest to Lowest...
(1) Provide Leadership
(2) Build Community
(3) Share Leadership
4 Develop People
5 Value People
6 Display Authenticity

$\Rightarrow$ By envisioning the future, taking initiative and clarifying goals

$\Rightarrow$ By building strong relationships, working collaboratively and valuing individual differences

$\Rightarrow$ By creating a shared vision and sharing decision-making power, status and privilege at all levels of the organization

$\Rightarrow$ By providing opportunities for learning, modeling appropriate behavior and building up others through encouragement

$\Rightarrow$ By listening receptively, serving the needs of others first and trusting in people

$\Rightarrow$ By integrity and trust, openness and accountibility and a willingness to learn from others

The following reports will provide you with an understanding of how your organization and leadership are perceived by those within the organization (top leadership, management, and the workforce). 


\section{EXECUTIVE SUMMARY}

Your Organizational Health . . .

\section{Health Level $=\operatorname{org}^{4} \ldots$ Moderate Health}

Workers experience this organization as a positively paternalistic (parental-led) organization characterized by a moderate level of trust and trustworthiness along with occasional uncertainty and fear. Creativity is encouraged as long as it doesn't move the organization too far beyond the status quo. Risks can be taken, but failure is sometimes feared. Goals are mostly clear, though the overall direction of the organization is sometimes confused. Leaders often take the role of nurturing parent while workers assume the role of the cared-for child. (See expanded description on page 7)

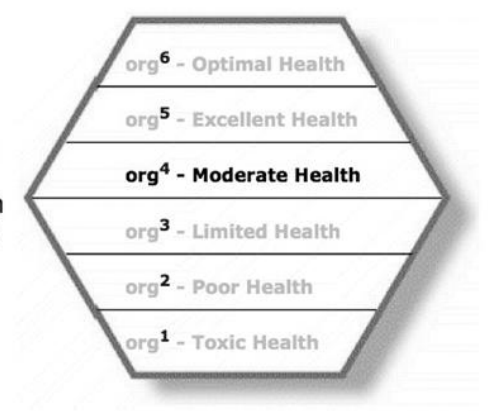

\begin{tabular}{|c|c|}
\hline HIGHEST KEY AREAS & LOWEST KEY AREAS \\
OF ORGANIZATIONAL HEALTH & OF ORGANIZATIONAL HEALTH \\
\hline $\begin{array}{l}\text { • Provide Leadership } \\
\text { Build Community }\end{array}$ & • Value People \\
\hline
\end{tabular}

Your Organizational Response ...

Organization being assessed
Unit Assessed (if applicable)
Group providing the assessment
Total number of respondents
Top Leadership respondents
Management respondents
Workforce respondents
Date of the assessment

Associação Central
Amazonas da Igreja
Adventista do Sétimo Dia
(ACeAm)
Total Organization
Total Organization
55
3
10
42
$7 / 9 / 2015$

Associação Central Adventista do Sétimo Dia (ACeAm)

Total Organization

$7 / 9 / 2015$ 


\section{Your Organizational Dynamics ...}

\section{PERCEPTION MATCH* = MODERATE MATCH (Page 9)}

(*between Top Leadership and Workforce)

The Top Leadership and the Workforce have a different perception of the current health status of the organization. This suggests a limited level of shared awareness and open communication.

\section{READINESS-FOR-CHANGE (RFC) = MODERATE RFC (Page 13)}

There is a moderate readiness-for-change within the organization. Workers and leaders possess a moderate level of energy for pursuing change, which suggests some ability exists to improve in the six key areas of organizational health. To increase readiness-for-change, first address awareness and open communication. Improving these areas through the sharing of these OLA results and facilitating open discussion around them will begin to create the readiness to move into greater organizational health.

\section{JOB SATISFACTION $=$ GOOD $($ Page 11$)$}

Workers believe that they personally are making a contribution to the organization and that their job is important to its success. They believe that they are able to use their best gifts and abilities in their job while being creative in their work. They enjoy the work they do and believe that they personally are working at a high level of productivity.

\section{KEY PATTERNS}

Workers perceive the Organization, as a whole, less positively than the Leadership (Page 10)

Leaders perceive the Organization, as a whole, less positively than the Leadership (Page 10)

Workers are looking for more responsibility and authority to do their jobs (Page 6)

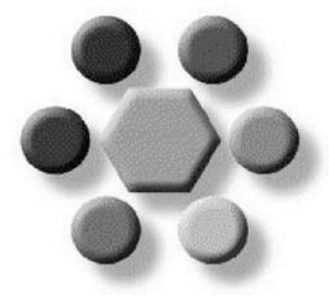

Copyright (C) 1998-2015 James A. Laub Version: 1.3 Page: 5 


\section{HEALTH LEVEL}

This is the average score of your organization's Workforce in the Six Key Areas compared to the average score of all organizations that have completed the OLA. It is the Workforce score that determines your organization's health level.

\begin{tabular}{|c|c|c|c|c|c|c|}
\hline & $\begin{array}{c}\text { Toxic Health } \\
\text { org }^{1}\end{array}$ & $\begin{array}{c}\text { Poor Health } \\
\text { org }^{2}\end{array}$ & $\begin{array}{l}\text { Limited Health } \\
\operatorname{org}^{3}\end{array}$ & $\begin{array}{c}\text { Moderate Health } \\
\operatorname{org}^{4}\end{array}$ & $\begin{array}{c}\text { Excellent Health } \\
\operatorname{org}^{5}\end{array}$ & $\begin{array}{c}\text { Optimal Health } \\
\operatorname{org}^{6}\end{array}$ \\
\hline \begin{tabular}{|l} 
Value \\
People
\end{tabular} & & & & & & \\
\hline
\end{tabular}
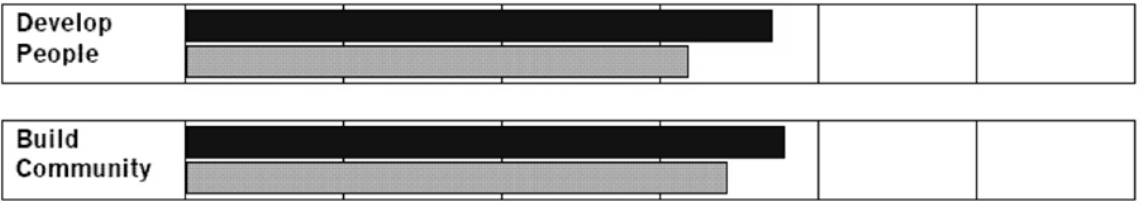

\begin{tabular}{|l|l|l|l|}
\hline Display \\
Authenticity
\end{tabular}
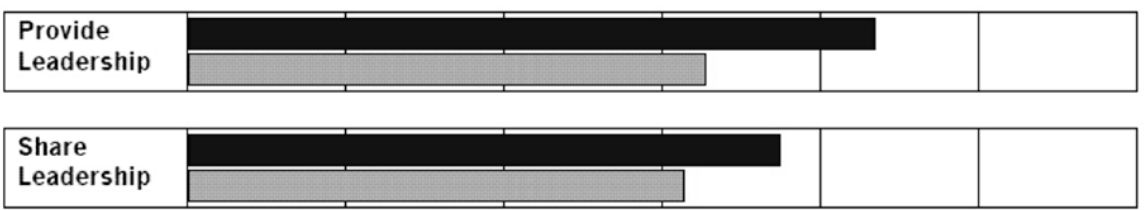

= Your Workforce average score

= Average score of all organizations who have taken the OLA

\section{KEY PATTERNS}

Your organization's highest key areas of organizational health were...

Provide Leadership

Build Community

Your organization's lowest key areas of organizational health were...

Value People

Display Authenticity

The relationship between the scores of "Provide Leadership" and "Share Leadership" indicates ...

Workers are looking for more responsibility and authority to do their jobs 


\section{$\operatorname{org}^{4}$ Description}

\section{Moderate to Good Organizational Health}

This organization is now operating with Moderate to Good Organizational Health in terms of its workers, leadership and organizational culture and it exhibits these characteristics throughout most levels of operation.

The Workers: Motivation, morale, attitude \& commitment, listening, relationships vs. tasks

Many workers sense they are valued while others are uncertain. People receive training in this organization in order to equip them to fulfill company goals. Workers are listened to but usually it is when they speak in line with the values and priorities of the leaders. Their ideas are often sought and sometimes used, but the important decisions remain at the top levels of the organization. Relationships are valued as they benefit company goals but organizational tasks often come first. There is a tension between the expectation of conformity and encouragement of diversity.

The Leadership: Power, decision-making, goals \& direction

Leadership is positively paternalistic in style and mostly comes from the top levels of the organization. Leaders often take the role of nurturing parent while workers assume the role of the cared-for child. Power is delegated for specific tasks and for specific positions within the organization. Workers are encouraged to share ideas for improving the organization. Goals are mostly clear though the overall direction of the organization is sometimes confused.

The Team: Community, collaboration and team learning

Some level of cooperative work exists, and some true collaboration. Teams are utilized but may compete against one another when resources are scarce.

The Culture: Authenticity, integrity, accountability, creativity, trust, service, communication

Workers are sometimes unsure of where they stand and how open they can be with one another and especially with those in leadership over them. This is an environment where some risks can be taken but failure is sometimes feared. Creativity is encouraged as long as it doesn't move the organization too much beyond the status quo. There is a moderate level of trust and trustworthiness along with occasional uncertainty and fear. People feel trusted but know that trust can be lost very easily. People are motivated to serve the organization because it is their job to do so and they are committed to doing good work. This is an environment characterized by openness between select groups of people.

The Outlook: Type of workers attracted, action needed

This is a positively paternalistic organization, that will attract good motivated workers but may find that the most creative will seek professional challenges elsewhere. Change here is ongoing but often forced by outside circumstances. Improvement is desired but difficult to maintain over time. The outlook for this organization is positive. Decisions need to be made to move toward more healthy organizational life. This organization is in a good position to move towards optimal health in the future.

Copyright (C) 1998-2015 James A. Laub Version: 1.3 Page: 7 




Copyright $\odot$ 1998-2015 James A. Laub Version: 1.3 Page: 8 


\section{PERCEPTION MATCH}

\section{The Six Key Areas}

This is your organization's average score in the six critical areas of organizational health based on the perception of different positions within your organization (top leadership, management and workforce).

\begin{tabular}{|c|c|c|c|c|c|c|}
\hline & $\begin{array}{l}\text { Toxic Health } \\
\text { org }^{1}\end{array}$ & $\begin{array}{l}\text { Poor Health } \\
\text { org }^{2}\end{array}$ & $\begin{array}{l}\text { Limited Health } \\
\operatorname{org}^{3}\end{array}$ & $\begin{array}{l}\text { Moderate Health } \\
\operatorname{org}^{4}\end{array}$ & $\begin{array}{c}\text { Excellent Health } \\
\text { org }\end{array}$ & $\begin{array}{l}\text { Optimal Health } \\
\operatorname{org}^{6}\end{array}$ \\
\hline \multirow{2}{*}{\multicolumn{7}{|c|}{$\begin{array}{l}\text { Value } \\
\text { People }\end{array}$}} \\
\hline & & & & & $\square$ & \\
\hline
\end{tabular}

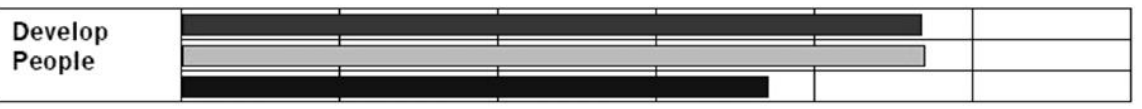

Build

Community

Display

Authenticity

Provide

Leadership
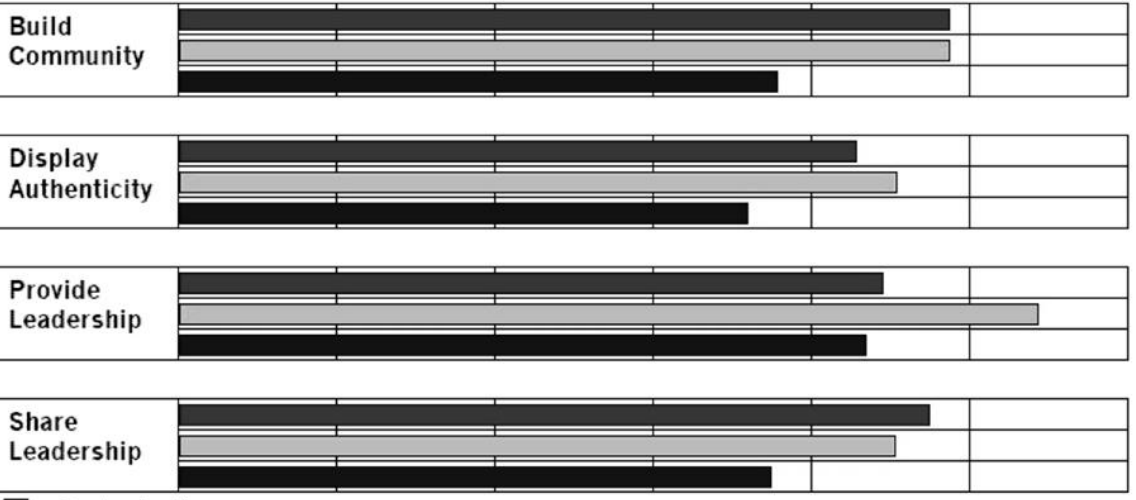

$=$ Top Leadership

Management/Supervisors

= Workforce

The Top Leadership and the Workforce have a different perception of the current health status of the organization. This suggests a limited level of shared awareness and open communication. 


\section{PERCEPTION MATCH}

\section{Organization \& Leadership}

The OLA also assesses your Organization, as a whole, in comparison to the Leadership of your organization (executive leaders and managers).

This report allows you to see:

1. A contrast of how your Organization and Leadership are perceived by those in the organization

2. A look at the different perceptions that may be present between different positions within your organization (workforce, managers, top leadership)

\begin{tabular}{|c|c|c|c|c|c|c|}
\multicolumn{1}{c|}{} & $\begin{array}{c}\text { Toxic Health } \\
\text { org }^{1}\end{array}$ & $\begin{array}{c}\text { Poor Health } \\
\text { org }^{2}\end{array}$ & $\begin{array}{c}\text { Limited Health } \\
\operatorname{org}^{3}\end{array}$ & $\begin{array}{c}\text { Moderate Health } \\
\operatorname{org}^{4}\end{array}$ & $\begin{array}{c}\text { Excellent Health } \\
\text { org }^{5}\end{array}$ & $\begin{array}{c}\text { Optimal Health } \\
\text { org }^{6}\end{array}$ \\
\hline \multirow{3}{*}{ Organization } & \multicolumn{3}{|l|}{} & \\
\cline { 2 - 6 } & & & & \\
\hline
\end{tabular}

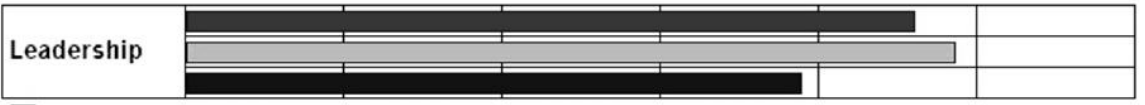

$=$ Top Leadership

= Management/Supervisors

= Workforce

\section{KEY PATTERNS IN YOUR ORGANIZATION}

\section{Comparison of Organization \& Leadership:}

- Workers perceive the Organization, as a whole, less positively than they do the Leadership

- Managers perceive the Organization, as a whole, less positively than they do the Leadership

- Top Leaders perceive the Organization, as a whole, less positively than they do the Leadership

\section{Difference in Perception between Top Leaders and Workforce:}

- Workers view the Organization less positively than the Top Leadership does

- Workers view the Leadership less positively than the Top Leadership does 


\section{Job Satisfaction}

\section{Response by Positions}

This report provides you with a summary of your organization's responses to the Job Satisfaction scale within the OLA assessment. It reveals whether your workers, managers and top leadership fall within, above, or below the average of all organizations that have taken the OLA.

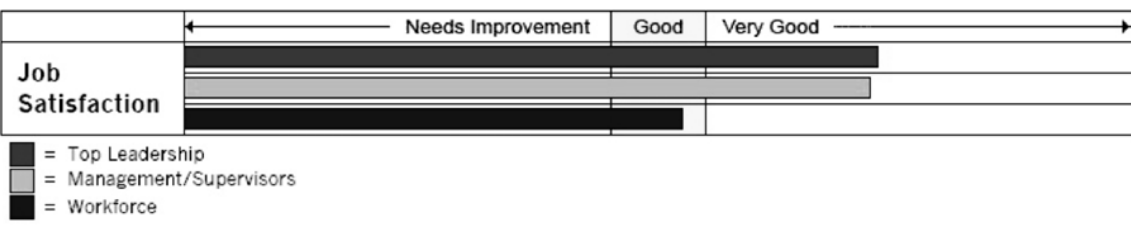

\section{Summary of Worker's perception:}

JOB SATISFACTION $=$ GOOD

Workers believe that they personally are making a contribution to the organization and that their job is important to its success. They believe that they are able to use their best gifts and abilities in their job while being creative in their work. They enjoy the work they do and believe that they personally are working at a high level of productivity.

\section{The following six factors were used to assess Job Satisfaction in your organization:}

- I feel good about my contribution to the organization

- My job is important to the success of the organization

- I am working at a high level of productivity

- I enjoy working in this organization

- I am able to be creative in my job

- I am able to use my best gifts and abilities in my job 


\section{Your organization's...}

\section{Readiness-for-Change}

You can move your organization towards optimal organizational health by increasing your Readiness-forChange (RFC). Two important ways this can be enhanced are by increasing your organization's Health Level and by increasing your organization's Perception Match. These two comprise the two scales on the Readinessfor-Change graph shown on the next page of this report.

\section{INCREASE YOUR PERCEPTION MATCH}

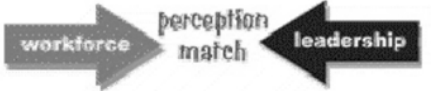

Your organization's Perception Match is determined by the closeness of perception between your leaders and the workforce regarding the presence and strength of the six Key Areas of organizational health. A low Perception Match on the RFC graph means that there is a significant gap between the perception held by the workforce and the perception of the leaders.

You can begin to close this perception gap and increase your Perception Match through an open, facilitated discussion of your organization's OLA results.

\section{INCREASE YOUR HEALTH LEVEL}

Your organization's Health Level is determined by the strength of the six critical characteristics of organizational health described on page 3 and measured on page 6 of this report. The higher the Health Level the stronger these characteristics exist in your

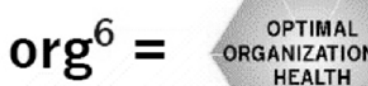
organization.

You can increase your Health Level by improving these six key areas of organizational health within all aspects and operations of your organization. 
Readiness-for-Change (RFC)



芉

There is a moderate readiness-for-change within the organization. Workers and leaders possess a moderate level of energy for pursuing change, which suggests some ability exists to improve in the six key areas of organizational health. To increase readiness-for-change, first address awareness and open communication. Improving these areas through the sharing of these OLA results and facilitating open discussion around them will begin to create the readiness to move into greater organizational health. 


\begin{tabular}{|c|l|l|l|l|l|l|}
\hline Workforce - Highest Six Scores & Org1 & Org2 & Org3 & Org4 & Org5 & Org6 \\
\hline PL & $\begin{array}{l}\text { Leaders in this organization communicate a clear vision } \\
\text { of the future of our organization }\end{array}$ & & & & \\
\hline VP & I am respected by those above me in the organization & & & & \\
\hline PL & $\begin{array}{l}\text { People in this organization know where this organization } \\
\text { is headed in the future }\end{array}$ & & & \\
\hline SL & $\begin{array}{l}\text { Leaders in this organization encourage each person in } \\
\text { the organization to exercise leadership }\end{array}$ & & & \\
\hline PL & $\begin{array}{l}\text { Leaders in this organization communicate clear plans \& } \\
\text { goals for the organization }\end{array}$ & & & \\
\hline DP & $\begin{array}{l}\text { Leaders in this organization create an environment that } \\
\text { encourages learning }\end{array}$ & & & \\
\hline
\end{tabular}

\begin{tabular}{|c|c|c|c|c|c|c|c|}
\hline \multicolumn{2}{|c|}{ Management/Supervisors - Highest Six Scores } & Org1 & Org2 & Org3 & Org4 & Org5 & Org6 \\
\hline PL & $\begin{array}{l}\text { Leaders in this organization communicate a clear vision } \\
\text { of the future of our organization }\end{array}$ & & & & & & \\
\hline DA & I trust the leadership of this organization & & & & & & \\
\hline PL & $\begin{array}{l}\text { Leaders in this organization provide the support and } \\
\text { resources needed to help workers meet their goals }\end{array}$ & & & & & & \\
\hline PL & $\begin{array}{l}\text { People in this organization are clear on the key goals of } \\
\text { the organization }\end{array}$ & & & & & & \\
\hline VP & I am listened to by those above me in the organization & & & & & & \\
\hline$B C$ & $\begin{array}{l}\text { Leaders in this organization facilitate the building of } \\
\text { community \& team }\end{array}$ & & & & & & \\
\hline
\end{tabular}

\begin{tabular}{|c|l|l|l|l|l|l|}
\hline Top Leaders - Highest Six Scores & Org1 & Org2 & Org3 & Org4 & Org5 & Org6 \\
\hline SL & $\begin{array}{l}\text { People in this organization are encouraged by } \\
\text { supervisors to share in making important decisions }\end{array}$ & & & \\
\hline DA & I trust the leadership of this organization & & & \\
\hline DP & $\begin{array}{l}\text { I receive encouragement and affirmation from those } \\
\text { above me in the organization }\end{array}$ & & & \\
\hline VP & I am listened to by those above me in the organization & & & \\
\hline VP & $\begin{array}{l}\text { I feel appreciated by my supervisor for what I contribute } \\
\text { to the organization }\end{array}$ & & & \\
\hline DA & $\begin{array}{l}\text { Leaders in this organization are accountable \& } \\
\text { responsible to others }\end{array}$ & & \\
\hline
\end{tabular}

\begin{tabular}{|lll|}
\hline $\mathrm{VP}=$ Values People & $\mathrm{DP}=$ Develops People & $\mathrm{BC}=$ Builds Community \\
$\mathrm{DA}=$ Displays Authenticity & $\mathrm{PL}=$ Provides Leadership & $\mathrm{SL}=$ Shares Leadership \\
\hline
\end{tabular}




\begin{tabular}{|c|l|l|l|l|l|l|}
\hline Workforce - Lowest Six Scores & Org1 & Org2 & Org3 & Org4 & Org5 & Org6 \\
\hline VP & People in this organization trust each other & & & & \\
\hline BC & $\begin{array}{l}\text { People in this organization allow for individuality of style } \\
\text { and expression }\end{array}$ & & & & \\
\hline DA & $\begin{array}{l}\text { Leaders in this organization admit personal limitations \& } \\
\text { mistakes }\end{array}$ & & & & \\
\hline SL & $\begin{array}{l}\text { People in this organization are encouraged by } \\
\text { supervisors to share in making important decisions }\end{array}$ & & & \\
\hline DA & $\begin{array}{l}\text { People in this organization are trustworthy } \\
\text { DA }\end{array}$ & $\begin{array}{l}\text { People in this organization are non-judgmental - they } \\
\text { keep an open mind }\end{array}$ & & & & \\
\hline
\end{tabular}

\begin{tabular}{|c|c|c|c|c|c|c|c|}
\hline \multicolumn{2}{|r|}{ Management/Supervisors - Lowest Six Scores } & Org1 & Org2 & Org3 & Org4 & Org5 & Org6 \\
\hline VP & People in this organization trust each other & & & & & & \\
\hline VP & People in this organization accept people as they are & & & & & & \\
\hline VP & $\begin{array}{l}\text { People in this organization are aware of the needs of } \\
\text { others }\end{array}$ & & & & & & \\
\hline SL & $\begin{array}{l}\text { People in this organization are encouraged by } \\
\text { supervisors to share in making important decisions }\end{array}$ & & & & & & \\
\hline DA & $\begin{array}{l}\text { Leaders in this organization are open to learning from } \\
\text { those who are below them in the organization }\end{array}$ & & & & & & \\
\hline VP & $\begin{array}{l}\text { People in this organization are caring \& compassionate } \\
\text { towards each other }\end{array}$ & & & & & & \\
\hline
\end{tabular}

\begin{tabular}{|c|l|l|l|l|l|l|}
\hline Top Leaders - Lowest Six Scores & Org1 & Org2 & Org3 & Org4 & Org5 & Org6 \\
\hline DA & $\begin{array}{l}\text { People in this organization demonstrate high integrity \& } \\
\text { honesty }\end{array}$ & & & & \\
\hline DA & People in this organization are trustworthy & & & & \\
\hline SL & $\begin{array}{l}\text { Leaders in this organization give workers the power to } \\
\text { make important decisions }\end{array}$ & & & & \\
\hline DA & $\begin{array}{l}\text { Leaders in this organization are open to receiving } \\
\text { criticism \& challenge from others }\end{array}$ & & & & \\
\hline VP & People in this organization trust each other & & & \\
\hline DA & $\begin{array}{l}\text { People in this organization maintain high ethical } \\
\text { standards }\end{array}$ & & & \\
\hline
\end{tabular}

\begin{tabular}{|lll|}
\hline $\mathrm{VP}=$ Values People & $\mathrm{DP}=$ Develops People & $\mathrm{BC}=$ Builds Community \\
$\mathrm{DA}=$ Displays Authenticity & $\mathrm{PL}=$ Provides Leadership & $\mathrm{SL}=$ Shares Leadership \\
\hline
\end{tabular}


This page is designed to contrast the Top Leader's response with that of the Workforce. If no Top Leaders completed the OLA for this organization this report page will be incomplete.

$=$ Top Leadership

= Workforce

This graph shows where the Top Leaders and the Workforce are in most agreement (Highest Perception Match).

\begin{tabular}{|c|c|c|c|c|c|c|c|}
\hline \multicolumn{2}{|c|}{ Highest Perception Match Items } & Org1 & Org2 & Org3 & Org4 & Org5 & \multirow[t]{2}{*}{ Org6 } \\
\hline DA & $\begin{array}{l}\text { Leaders in this organization promote open } \\
\text { communication and sharing of information }\end{array}$ & \multicolumn{4}{|c|}{20} & & \\
\hline \multirow{2}{*}{ SL } & Leaders in this organization give workers the power to & & & & & & \\
\hline & make important decisions & & & & & & \\
\hline \multirow{2}{*}{ PL } & People in this organization know where this organization & & & & & & \\
\hline & is headed in the future & & & & & & \\
\hline VP & I am respected by those above me in the organization & & & & & & \\
\hline \multirow{2}{*}{ PL } & & & & & & & \\
\hline & the organization & & & & & & \\
\hline \multirow{2}{*}{ PL } & Leaders in this organization communicate a clear vision & & & & & & \\
\hline & of the future of our organization & & & & & & \\
\hline
\end{tabular}

This graph shows where the Top Leaders and the Workforce are in least agreement (Highest Perception Match).

\begin{tabular}{|c|c|c|c|c|c|c|c|}
\hline \multicolumn{2}{|c|}{ Lowest Perception Match Items } & Org1 & Org2 & Org3 & Org4 & Org5 & Org6 \\
\hline \multirow[t]{2}{*}{ SL } & \multirow{2}{*}{$\begin{array}{l}\text { People in this organization are encouraged by } \\
\text { supervisors to share in making important decisions }\end{array}$} & & & & & & \\
\hline & & & & & & & \\
\hline \multirow{2}{*}{ DA } & \multirow{2}{*}{$\begin{array}{l}\text { People in this organization are non-judgmental - they } \\
\text { keep an open mind }\end{array}$} & & & & & & \\
\hline & & & & & & & \\
\hline \multirow{2}{*}{ SL } & \multirow{2}{*}{$\begin{array}{l}\text { Leaders in this organization allow workers to help } \\
\text { determine where this organization is headed }\end{array}$} & & & & & & \\
\hline & & & & & & & \\
\hline \multirow{2}{*}{$B C$} & \multirow{2}{*}{$\begin{array}{l}\text { Leaders in this organization work alongside the workers } \\
\text { instead of separate from them }\end{array}$} & & & & & & \\
\hline & & & & & & & \\
\hline \multirow{2}{*}{ VP } & \multirow{2}{*}{$\begin{array}{l}\text { I feel appreciated by my supervisor for what I contribute } \\
\text { to the organization }\end{array}$} & & & & & & \\
\hline & & & & & & & \\
\hline \multirow{2}{*}{$\mathrm{BC}$} & \multirow{2}{*}{$\begin{array}{l}\text { People in this organization allow for individuality of style } \\
\text { and expression }\end{array}$} & & & & & & \\
\hline & & & & & & & \\
\hline \multirow{2}{*}{\multicolumn{2}{|c|}{$\begin{array}{l}\text { VP }=\text { Values People } \\
D A=\text { Displays Authenticity }\end{array}$}} & & \multicolumn{5}{|c|}{$\mathrm{BC}=$ Builds Community } \\
\hline & $\mathrm{DA}=$ Displays Authenticity & & \multicolumn{5}{|c|}{ SL $=$ Shares Leadership } \\
\hline
\end{tabular}


This page is designed to contrast the Management/Supervisor's response with that of the Workforce. If no Managers/Supervisors completed the OLA for this organization this report page will be incomplete.

= Management/Supervisors

= Workforce

This graph shows where the Managers/Supervisors and the Workforce are in most agreement (Highest Perception Match).

\begin{tabular}{|c|l|l|l|l|l|l|}
\hline Highest Perception Match Items & Org1 & Org2 & Org3 & Org4 & Org5 & Org6 \\
\hline BC & $\begin{array}{l}\text { Leaders in this organization encourage workers to work } \\
\text { together rather than competing against each other }\end{array}$ & & \\
\hline VP & People in this organization accept people as they are & & & \\
\hline VP & People in this organization trust each other & & & \\
\hline SL & $\begin{array}{l}\text { Leaders in this organization encourage each person in } \\
\text { the organization to exercise leadership }\end{array}$ & & \\
\hline DA & $\begin{array}{l}\text { Leaders in this organization promote open } \\
\text { communication and sharing of information }\end{array}$ & & \\
\hline DA & $\begin{array}{l}\text { Leaders in this organization are open to learning from } \\
\text { those who are below them in the organization }\end{array}$ & & \\
\hline
\end{tabular}

This graph shows where the Managers/Supervisors and the Workforce are in least agreement (Highest Perception Match).

\begin{tabular}{|c|c|c|c|c|c|c|c|}
\hline \multicolumn{2}{|c|}{ Lowest Perception Match Items } & Org1 & Org2 & Org3 & Org4 & Org5 & Org6 \\
\hline \multirow{2}{*}{ DA } & \multirow{2}{*}{$\begin{array}{l}\text { Leaders in this organization admit personal limitations \& } \\
\text { mistakes }\end{array}$} & & & & & & \\
\hline & & & & & & & \\
\hline \multirow{2}{*}{ BC } & \multirow{2}{*}{$\begin{array}{l}\text { People in this organization allow for individuality of style } \\
\text { and expression }\end{array}$} & & & & & & \\
\hline & & & & & & & \\
\hline \multirow{2}{*}{$\mathrm{BC}$} & \multirow{2}{*}{$\begin{array}{l}\text { Leaders in this organization work alongside the workers } \\
\text { instead of separate from them }\end{array}$} & & & & & & \\
\hline & & & & & & & \\
\hline \multirow{2}{*}{$\mathrm{BC}$} & \multirow{2}{*}{$\begin{array}{l}\text { Leaders in this organization facilitate the building of } \\
\text { community \& team }\end{array}$} & & & & & & \\
\hline & & & & & & & \\
\hline DA & I trust the leadership of this organization & & & & & & \\
\hline \multirow{2}{*}{ PL } & \multirow{2}{*}{$\begin{array}{l}\text { Leaders in this organization encourage people to take } \\
\text { risks even if they may fail }\end{array}$} & & & & & & \\
\hline & & & & & & & \\
\hline \multicolumn{2}{|c|}{ VP $=$ Values People } & & \multicolumn{5}{|c|}{$\mathrm{BC}=$ Builds Community } \\
\hline \multicolumn{2}{|c|}{ DA = Displays Authenticity } & & \multicolumn{5}{|c|}{ SL $=$ Shares Leadership } \\
\hline
\end{tabular}


This page is designed to contrast the Top Leader's response with that of the Management/Supervisors. If no Top Leaders or Managers/Supervisiors completed the OLA for this organzation this report page will be incomplete.

$=$ Top Leadership

$=$ Management $/$ Supervisors

This graph shows where the Top Leaders and the Managers/Supervisors are in most agreement (Highest Perception Match).

\begin{tabular}{|c|c|c|c|c|c|c|c|}
\hline \multicolumn{2}{|c|}{ Highest Perception Match Items } & Org1 & Org2 & Org3 & Org4 & Org5 & \multirow[t]{2}{*}{ Org6 } \\
\hline \multirow{2}{*}{ DA } & \multirow{2}{*}{$\begin{array}{l}\text { People in this organization maintain high ethical } \\
\text { standards }\end{array}$} & \multicolumn{4}{|c|}{  } & & \\
\hline & & & & & & & \\
\hline \multirow{2}{*}{ VP } & Leaders in this organization put the needs of the & & & & & & \\
\hline & workers ahead of their own needs & & & & & & \\
\hline $\mathrm{BC}$ & People in this organization relate well to each other & & & & & & \\
\hline \multirow[b]{2}{*}{ DP } & & & & & & & \\
\hline & $\begin{array}{l}\text { Leaders in this organization practice the same behavior } \\
\text { they expect from others }\end{array}$ & & & & & & \\
\hline \multirow{2}{*}{ DP } & Leaders in this organization lead by example by modeling & & & & & & \\
\hline & appropriate behavior & & & & & & \\
\hline \multirow{2}{*}{ DA } & Leaders in this organization are accountable \& & & & & & & \\
\hline & responsible to others & & & & & & $\square$ \\
\hline
\end{tabular}

This graph shows where the Top Leaders and the Managers/Supervisors are in least agreement (Highest Perception Match).

\begin{tabular}{|c|c|c|c|c|c|c|c|}
\hline \multicolumn{2}{|c|}{ Lowest Perception Match Items } & Org1 & Org2 & Org3 & Org4 & Org5 & Org6 \\
\hline \multirow{2}{*}{$\mathrm{SL}$} & \multirow{2}{*}{$\begin{array}{l}\text { People in this organization are encouraged by } \\
\text { supervisors to share in making important decisions }\end{array}$} & & & & & & \\
\hline & & & & & & & \\
\hline \multirow{2}{*}{ PL } & Leaders in this organization provide the support and & & & & & & \\
\hline & resources needed to help workers meet their goals & & & & & & \\
\hline VP & People in this organization trust each other & & & & & & \\
\hline \multirow{2}{*}{ SL } & Leaders in this organization allow workers to help & & & & & & \\
\hline & determine where this organization is headed & & & & & & \\
\hline \multirow{2}{*}{ PL } & Leaders in this organization take appropriate action & & & & & & \\
\hline & when it is needed & & & & & & ] \\
\hline \multirow[t]{2}{*}{ PL } & Leaders in this organization communicate a clear vision & & & & & & \\
\hline & of the future of our organization & & & & & & \\
\hline
\end{tabular}

\begin{tabular}{|lll|}
\hline VP $=$ Values People & DP $=$ Develops People & BC $=$ Builds Community \\
DA = Displays Authenticity & PL $=$ Provides Leadership & SL $=$ Shares Leadership \\
\hline
\end{tabular}


Detailed Report

...Results by Individual Items











\begin{tabular}{|c|c|c|c|c|c|c|c|}
\hline \multirow{2}{*}{29} & \multirow{2}{*}{$\begin{array}{l}\text { Leaders in this organization work alongside the workers } \\
\text { instead of separate from them }\end{array}$} & \multirow{2}{*}{\multicolumn{6}{|c|}{ 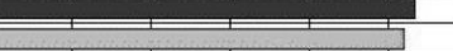 }} \\
\hline & & & & & & & \\
\hline \multicolumn{2}{|c|}{ Display Authenticity } & Org1 & Org2 & Org3 & Org4 & Org5 & Org6 \\
\hline \multirow{2}{*}{30} & \multirow{2}{*}{$\begin{array}{l}\text { People in this organization are non-judgmental - they } \\
\text { keep an open mind }\end{array}$} & \multirow{2}{*}{\multicolumn{5}{|c|}{ 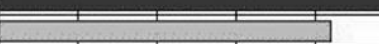 }} & \\
\hline & & & & & & & \\
\hline \multirow{2}{*}{31} & \multirow{2}{*}{ People in this organization are trustworthy } & & & & & & \\
\hline & & & & & & & \\
\hline \multirow{2}{*}{32} & \multirow{2}{*}{$\begin{array}{l}\text { People in this organization demonstrate high integrity \& } \\
\text { honesty }\end{array}$} & & & & & & \\
\hline & & & & & & & \\
\hline & & & & & & & \\
\hline 33 & standards & & & & & & \\
\hline \multirow[b]{2}{*}{34} & \multirow{2}{*}{$\begin{array}{l}\text { Leaders in this organization admit personal limitations \& } \\
\text { mistakes }\end{array}$} & & & & & & \\
\hline & & & & & & & \\
\hline & leaders in this organization promete onen & & & & & & \\
\hline 35 & communication and sharing of information & & & & & & \\
\hline \multirow{2}{*}{36} & \multirow{2}{*}{$\begin{array}{l}\text { Leaders in this organization are accountable \& } \\
\text { responsible to others }\end{array}$} & & & & & & \\
\hline & & & & & & & \\
\hline \multirow{2}{*}{37} & \multirow{2}{*}{$\begin{array}{l}\text { Leaders in this organization are open to learning from } \\
\text { those who are below them in the organization }\end{array}$} & & 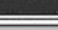 & = & & & \\
\hline & & & & & & & \\
\hline & Leaders in this organization honestly evaluate & & & & & & \\
\hline 38 & themselves before seeking to evaluate others & $\overline{-2}$ & 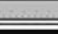 & & & & \\
\hline \multirow{2}{*}{39} & \multirow{2}{*}{$\begin{array}{l}\text { Leaders in this organization are open to receiving } \\
\text { criticism \& challenge from others }\end{array}$} & & & & & & \\
\hline & & & & & & & \\
\hline \multirow{2}{*}{40} & \multirow{2}{*}{$\begin{array}{l}\text { Leaders in this organization say what they mean, and } \\
\text { mean what they say }\end{array}$} & & & & & & \\
\hline & & & & & & & \\
\hline \multirow{2}{*}{41} & \multirow{2}{*}{ I trust the leadership of this organization } & $\overline{\bar{E}}$ & & $\overline{\bar{E}}$ & & 至 & \\
\hline & & & $=\mathrm{C}_{\mathrm{O}} \mathrm{C}$ & & & & \\
\hline \multicolumn{2}{|c|}{ Provide Leadership } & Org1 & Org2 & Org3 & Org4 & Org5 & Org6 \\
\hline \multirow{2}{*}{42} & \multirow{2}{*}{$\begin{array}{l}\text { People in this organization know where this organization } \\
\text { is headed in the future }\end{array}$} & & & & $=$ & & \\
\hline & & & & & & & \\
\hline
\end{tabular}




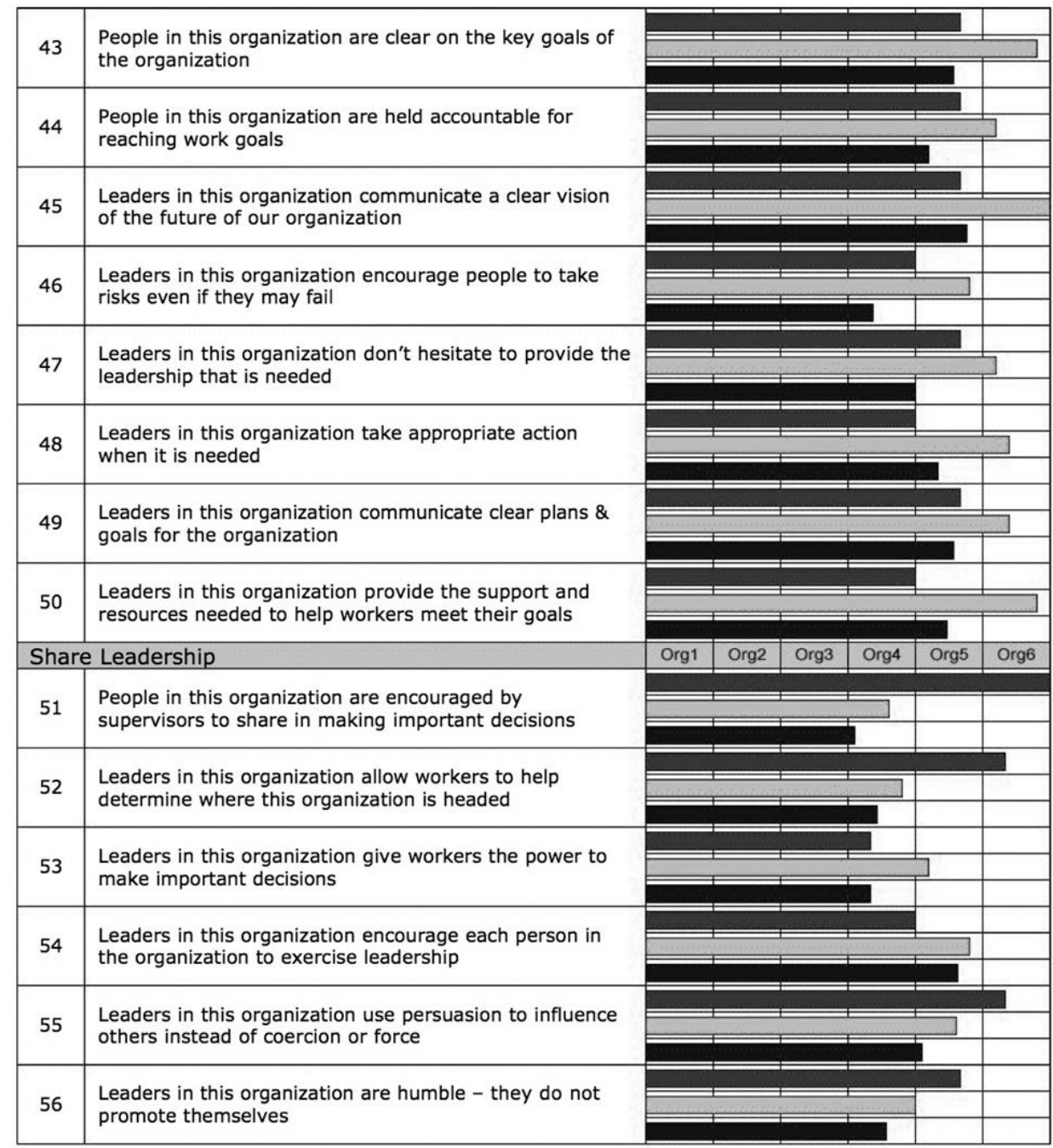




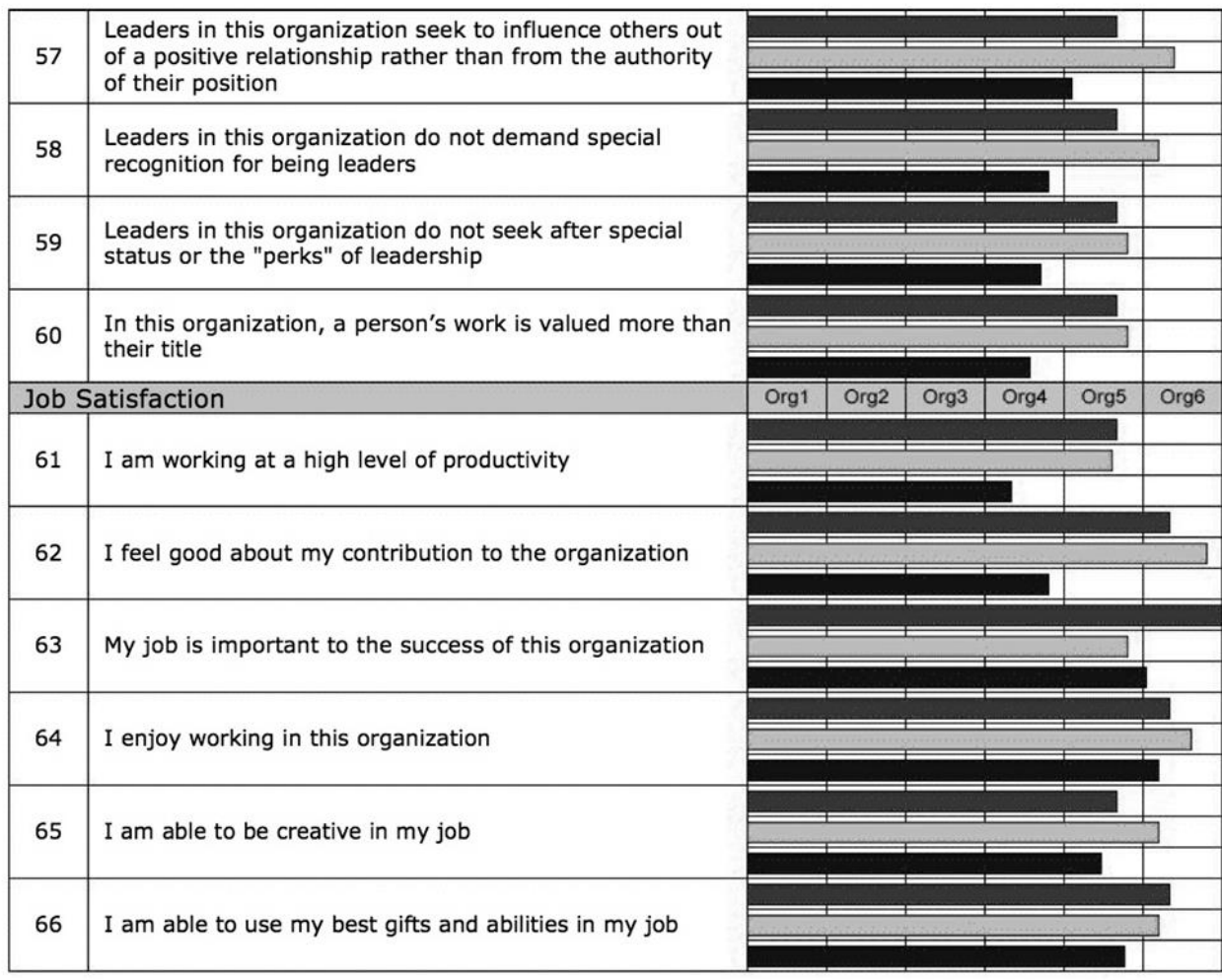

= Top Leadership

= Management/Supervisors

$=$ Workforce 


\section{Build your organization...}

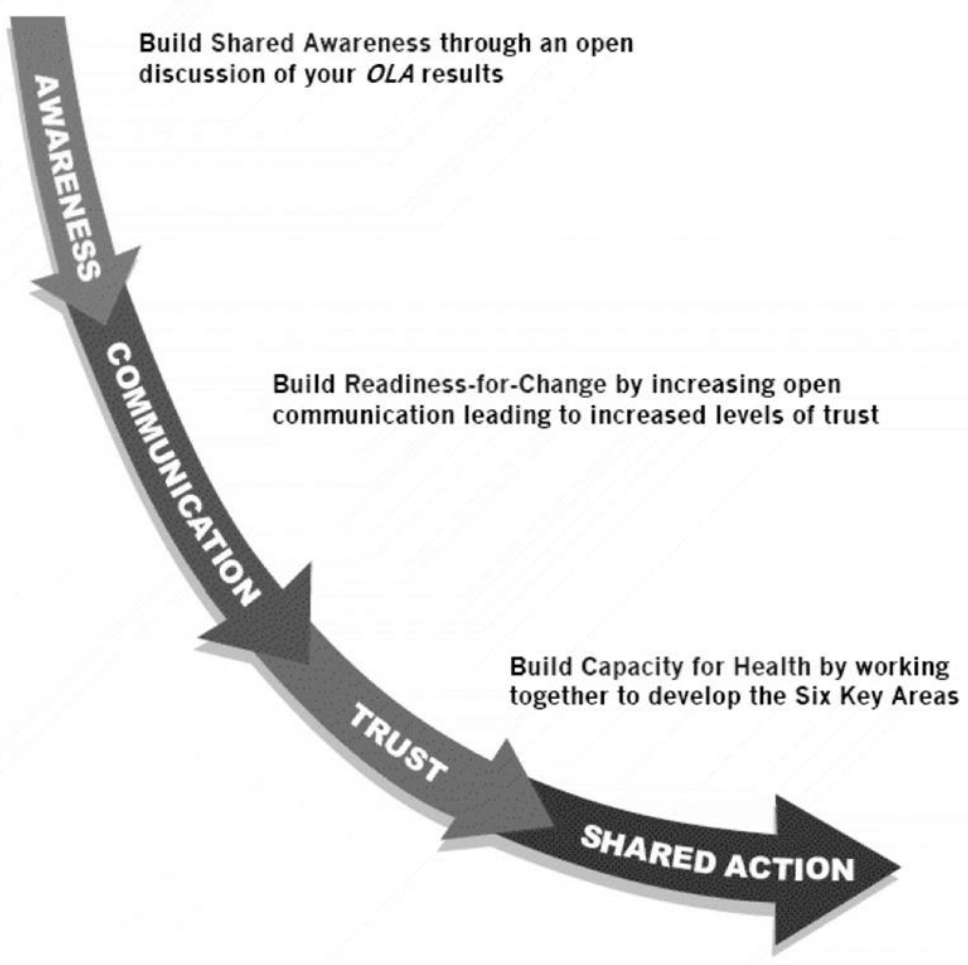

...to achieve optimal organizational health 
We can partner with you at all levels

For group facilitation, training and coaching, contact:

$$
\begin{aligned}
& \text { Dr. Jim Laub, OLAgroup } \\
& \text { ola@OLAGroup.com }
\end{aligned}
$$

www.OLAGroup.com 
OLAgroup - The OLAgroup is a network of organizational coaches and trainers who are committed to helping your organization establish optimal organizational health. These OLAgroup partners are specifically trained in utilizing the OLA to assess the current health of your organization, to determine your readiness for change and to assist you in finding the best path toward positive and healthy chanqe.

OLA - the OLA is a 66 item web-delivered assessment that provides an assessment of organizational health from a values-based (servant) leadership perspective. The instrument is designed to be taken by people at all position levels of the organization (Top Leaders, Supervisors/Managers \& Workforce). The report provides an

organizational health level, perception match between the 3 position levels and Readiness-for-Change. The OLA takes about 15 minutes to complete and sub-group reports can be delivered along with an overall orqanizational analysis.

\section{OA $36 \mathrm{C}^{\circ}$}

\section{... assess the health of individual employees and leaders}

OLA360 - the OLA360 is a web-based review tool that facilitates anonymous, multiangle performance assessment of both individuals and organizations. Individuals can be reviewed from the perspective of self, manager, coworkers, customers and direct reports. These reviews provide concrete, result-based feedback and encourage open interaction and communication - driving strategies for personal and professional improvement for all employees in the orqanization.

\section{OLApartners ... assess the health of individual employees and leaders}

OLApartners - if you desire to use the OLA products to help organizations to become healthier contact us to see about credentialing training in the use of the OLA instruments and process. 


\section{REFERÊNCIAS}

Adventist Church Management System. (2009). Retirado de www.acmsnet.org

Alaby, J. A. (2006). Líderes devem ser filósofos?. In J. F. Oliveira \& R. M. Marinho (Orgs.), Liderança: Uma questão de competência (pp. 23-51). São Paulo, Brasil: Saraiva.

Aquino, C. P. (1980). Administração de pessoal. São Paulo, Brasil: Atlas.

Behrens, A. (2010). Os erros e acertos do líder paternalista. Retirado de http://www.cimentoitambe.com.br/lideranca-paternalista-a-preferida-entrebrasileiros/

Bergamini, C. W. (2009). Liderança: Administração do sentido [iBook Version]. São Paulo, Brasil: Atlas. Retirado de http://www.apple.com/br/ibooks/

Blanchard, K. (1996). Virando ao contrário a pirâmide organizacional. In F. Hesselbein, M. Goldsmith, \& R. Beckhard (Eds), O líder do futuro (pp. 99103). São Paulo, Brasil: Futura.

Blanchard, K. (2011). Liderança de alto nível: Como criar e liderar organizações de alto desempenho. Porto Alegre, Brasil: Bookman.

Bossidy, L. \& Charan, R. (2015). Execução: A disciplina para atingir resultados. Rio de Janeiro, Brasil: Elsevier.

Brandão, João B. (2013). Gestão estratégica de recursos humanos. $1^{\mathrm{a}} \mathrm{ed}$. Rio de Janeiro, Brasil: Editora FGV.

Burns, J. M. (1978). Leadership. New York, NY: Perineum.

Burns, J. M. (1995). The crisis of leadership. In J. T. Wren (Ed.), The leader's companion: Insights on leadership through the ages (pp. 8-10). New York, NY: The Free Press.

Charan, R. (2007). Know-how: As 8 competências que separam os que fazem dos que não fazem. Rio de Janeiro, Brasil: Elsevier.

Charan, R. (2008). O líder criador de líderes. Rio de Janeiro, Brasil: Elsevier.

Charan, R. (2010). Execução: a disciplina para atingir resultados. Rio de Janeiro, Brasil: Elsevier. 
Charan. R. \& Conaty, B. (2011). A arte de cultivar líderes: Como se tornar um mestre na criação de talentos. Rio de Janeiro, Brasil: Elsevier.

Chiavenato, I. (2014a). Gestão de pessoas: O novo papel dos recursos humanos nas organizações ( $4^{\mathrm{a}}$ ed.). Barueri, Brasil: Manole.

Chiavenato, I. (2014b). Teoria geral da administração (9a ed.). Barueri, Brasil: Editora Manole.

Chiavenato, I (2014c). Administração nos novos tempos: Os novos horizontes em administração, (3 ed.). Barueri, Brasil: Editora Manole.

Collins, J. (2013). Empresas feitas para vencer. São Paulo, Brasil: Elsevier.

Covey, S. R. (2002). Liderança baseada em princípios, (5 ed.). Rio de Janeiro, Brasil: Elsevier.

Covey, S. R. (2005). O $8^{a}$ Hábito: Da eficácia à grandeza. Rio de Janeiro, Brasil: Elsevier.

Covey, S. R. (2008). A velocidade da confiança: o elemento que faz toda diferença, ( $3^{\text {a }}$ ed.). Rio de Janeiro, Brasil: Elsevier.

Covey, S. R. (2010). Os sete hábitos das pessoas altamente eficazes, (40a ed.). Rio de Janeiro, Brasil: BestSeller.

Diehl, A. A. (2004). Pesquisa em ciências sociais aplicadas: Métodos e técnicas. São Paulo, Brasil: Prentice Hall.

George, B., \& Sims, P. (2012). Autenticidade: O segredo do bom líder é ser fiel a seus princípios. São Paulo, Brasil: Saraiva.

Goleman, D. (2015). Liderança: a inteligência emocional na formação de um líder de sucesso, $\left(1^{\mathrm{a}}\right.$ ed.). Rio de Janeiro, Brasil: Objetiva.

Greenleaf, R. K. (1998). The leadership crisis: A message for college and university faculty. In L. C. Spears, (Ed.), Robert K. Greenleaf: The power of servant leadership, (pp. 77-92). Oakland, CA: Berrett-Koehler Publishers.

Greenleaf, R. K. (2002). Servant leadership: A journey into the nature of legitimate power \& greatness. New York, NY: Paulist Press. http://dx.doi.org/10.1590/S1678-69712011000100003

Guerra, T. G. (2008). Cómo planear una investigación empírica: Una experiencia de autoaprendizage. Montemorelos, México: Editorial Montemorelos.

Hunter, J. C. (2006). Como se tornar um líder servidor. Rio de Janeiro, Brasil: Sextante. 
Kellerman, B. (2012). O fim da liderança: Como a liderança mudou e de forma podemos resgatar sua importância. Rio de Janeiro, Brasil: Elsevier.

Kotter, J. P. (2013). Liderando mudanças. Rio de Janeiro, Brasil: Elsevier.

Kouzes, J. M., \& Posner, B. Z. (2013). O desafio da liderança: Como aperfeiçoar sua capacidade de liderar. ( $5^{\mathrm{a}}$ ed.). Rio de Janeiro, Brasil: Elsevier.

Laub, J. (1999). Assessing the servant organization: Development of the servant organizational leadership (SOLA) instrument. Boca Raton, FL: Dissertation International. Retirado de http://www.olagroup.net/Images/mmDocument/Laub\%20Dissertation\%20Co mplete\%2099.pdf

Laub, J. (2015). Organizational leadership assessment: Evaluation report for Associação Central Amazonas da Igreja Adventista do Sétimo Dia. West Palm Beach, FL.

Lewis, R., \& Noble, J. (2015). Servant-leadership: Bringing the spirit of work to work. ( $1^{\text {a }}$ ed.).Oxford, Reino Unido: Management Books.

Lisboa, T. C. (2006). Pessoas: A razão de ser da liderança. In J. F. Oliveira \& R. M. Marinho (Orgs.), Liderança: Uma questão de competência (pp. 159-175). São Paulo, Brasil: Saraiva.

Locke, E. A. (1976). The nature and causes of job satisfaction. In M. D. Dunnette (Ed.). Handbook of industrial and organizational psychology, (pp. 12971349). Chicago, IL: Rand McNally.

Manual da Igreja Adventista do Sétimo Dia. (2016). Tradução Ranieri Sales. (22a ed.). Tatuí, Brasil: Casa Publicadora Brasileira.

Marcon, J. L. (2015). Documentos Internos da Associação Central Amazonas. Manaus, Brasil: ACeAm.

Marinho, R. M. (2006). Liderança em teoria e prática. In J. F. Oliveira \& R. M. Marinho (Orgs.), Liderança: Uma questão de competência (pp. 8-22). São Paulo, Brasil: Saraiva.

Martinez, M. C., \& Paraguay, A. I. B. B. (2003). Satisfação e saúde no trabalho: Aspectos conceituais e metodológicos. Cadernos de Psicologia Social do Trabalho, 6, 59-78. Retirado de www.revistas.usp.br/cpst/article/download/25851/27583

McChesney, C., Covey, S., \& Huling, J. (2013). As 4 disciplinas da execução: Garanta o foco nas metas crucialmente importantes. Rio de Janeiro, Brasil: Elsevier. 
Miguel, J. I. (2009). Organizational leadership: A study of the percptions of servant leadership pratices and beliefs, and its implications for a private christian institution of higher education in Brazil. Doctoral Dissertation. Andrews University: Berrien Springs, MI.

Migueles, C., \& Zanini, M. T. (2009). Liderança baseada em valores. Rio de Janeiro, Brasil: Campus.

Murray, A (2011). Gestão de empresas: The Wall Street Jornal. Rio de Janeiro, Brasil: Elsevier.

Neto, J. P. B. (2006). Ética: Competência que faz a diferença. In J. F. Oliveira \& R. M. Marinho (Orgs.), Liderança: Uma questão de competência, (pp. 193-214). São Paulo, Brasil: Saraiva.

Robbins, S. P. (2010). Comportamento organizacional. (14 ${ }^{\mathrm{a}}$ ed.). São Paulo, Brasil: Pearson Prentice Hall.

Robbins, S. P. (2015). Lidere e inspire: a verdade sobre a gestão de pessoas. São Paulo, Brasil: Saraiva.

Senge, P. M. (2014). A quinta disciplina: A arte e prática da organização que aprende. (30 ed.). Rio de Janeiro, Brasil: Best Seller.

Seventh-Day Adventist Yearbook. (2014). Hagerstown, MD: Review and Herald Publishing Association.

Spears, L. C. (1998). The power of servant-leadership. San Francisco, CA: BerretKoehler Publishers.

Teixiera, A. (2012). Felicidade S. A.: Por que a satisfação com o trabalho é a utopia possível para o século 21. Porto Alegre, Brasil: Arquipélago Editorial.

Tortorette, M. (2010). Os erros e acertos do líder paternalista. Retirado de http://www.catho.com.br/carreira-sucesso/sem-categoria/os-erros-e-acertosdolider-paternalistaeixiera

Vizeu, F. (2011). Uma aproximação entre liderança transformacional e teoria da ação comunicativa. Revista de Administração Mackenzie, 12 (1), 58-81.

Whamond, C. (2012). Key leadership. 2012. (iBooks edition). Retirado de https://itun.es/br/spiPD.nspires them.

Wheatley, M. J. (2006). Liderança e a nova ciência: Descobrindo ordem num mundo caótico. São Paulo, Brasil: Cultrix.

Wilkes, C. G. (1999). O último degrau da liderança. São Paulo, Brasil: Mundo Cristão. 